\title{
'DIFFERENT FROM ANY OTHER': \\ THE EXPERIENCE OF A LEBANESE MIGRANT \\ IN WELLINGTON \\ IN THE MID-TWENTIETH CENTURY
}

\author{
BY \\ MARINA JOSEPH FONTEIN
}

\begin{abstract}
A thesis
submitted to the Victoria University of Wellington

in partial fulfilment

of the requirements for the Degree of

Master of Arts (Applied) in Social Science Research
\end{abstract}

Victoria University of Wellington 


\section{ABSTRACT}

Aiming to cast insight on the Lebanese community in Wellington in the mid-twentieth century, a series of in-depth narrative history interviews explore aspects of the reflections of Lebanese migrant, Elias Arraj, who arrived in Wellington in 1953. A secondary data source comprising archived oral histories undertaken with members of the Dunedin Lebanese community in 1988 provides a background context, and additional insights on 'being Lebanese' in New Zealand.

The research design comprises a constructionist epistemology, a critical theoretical orientation and a narrative inquiry methodology. The interpretation of both primary and secondary data sources employs a thematic analysis. The roles of the researcher and the participants in the construction of the data and the impact of underlying social and cultural factors on the narrators' experiences are also explored.

Considering the cultural inheritance and religious affiliations which were important to Elias the thesis focuses on: his experience of immigration and re-settlement; the way he interpreted and responded to the difficulties he faced as a new migrant; and available avenues of support. The narratives reveal how Elias drew on his distinct and enduring sense of cultural heritage to overcome the challenge of being an immigrant in New Zealand. 


\section{ACKNOWLEDGEMENTS}

Sincere thanks to my supervisor Dr Annette Beasley, for her valued assistance and encouragement.

Special thanks to Elias Arraj, Lucia Arraj Stechman, and Karen ArrajFisher for sharing their family stories with me.

A big thank you to my own family especially to Eric, Celeste, and Danica.

\section{DEDICATION}

This thesis is dedicated to the memory of my grandfather

\section{Joseph Maroon-Joseph}

1908-1964 


\section{TABLE OF CONTENTS}

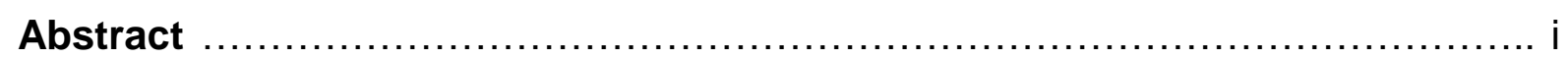

Acknowledgements and Dedication ................................................. ii

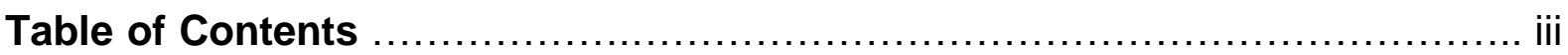

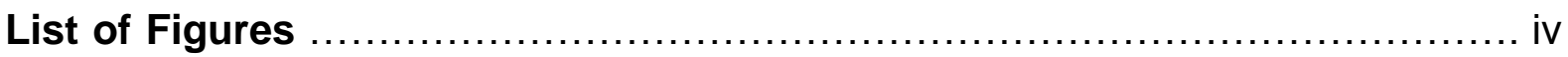

Chapter I: Introduction, Background, and Review of the Literature 1

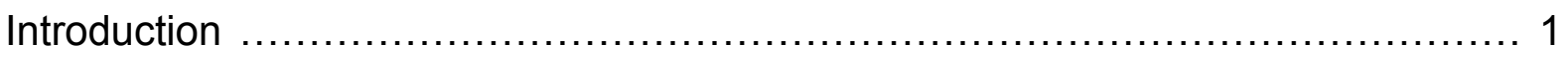

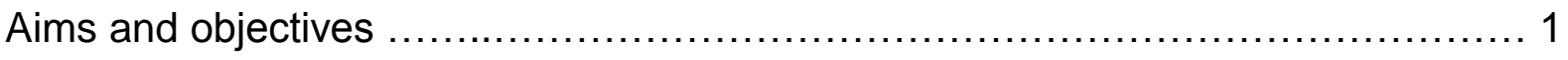

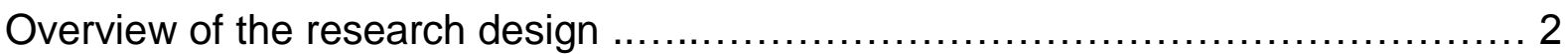

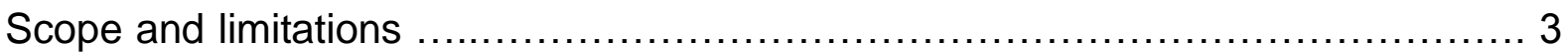

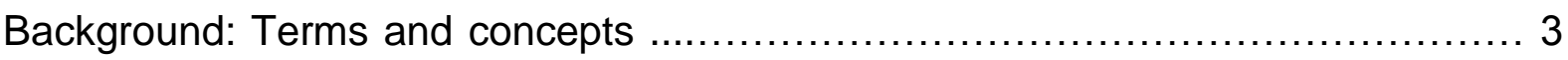

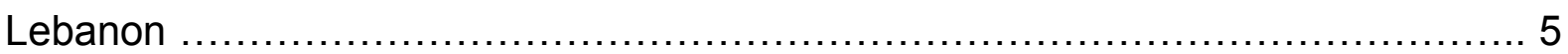

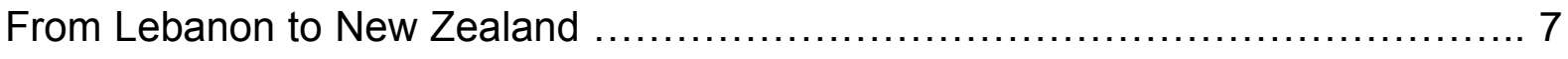

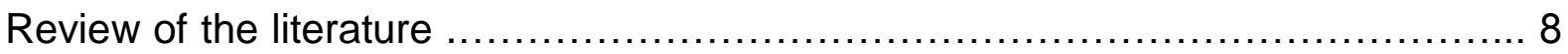

$\begin{array}{ll}\text { Chapter II: Research Design and Methodology } & 17\end{array}$

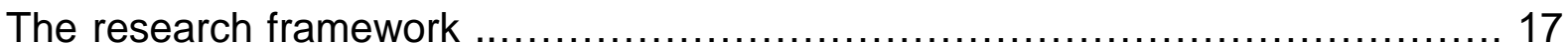

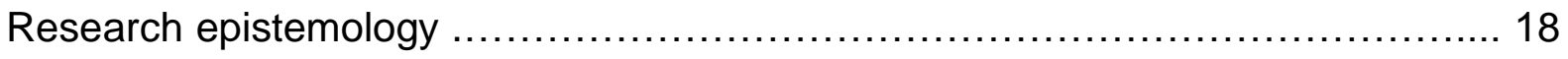

Critical theoretical approach ...................................................... 19

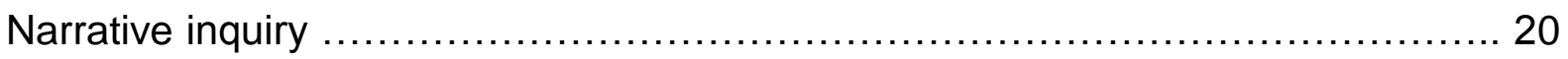

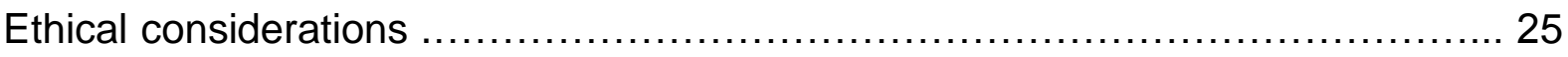

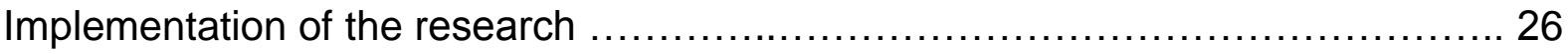

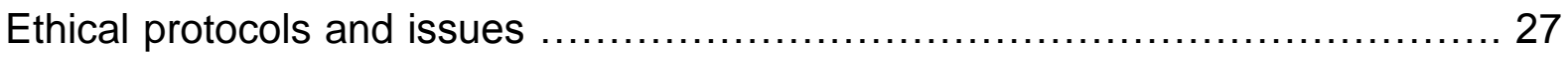

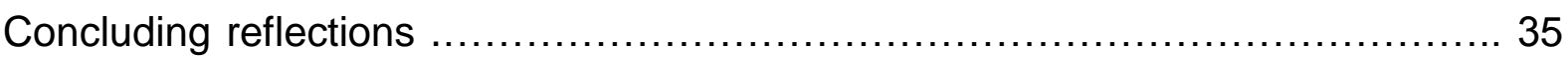




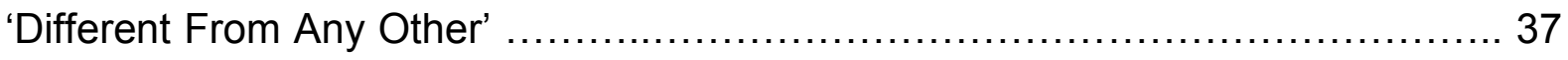

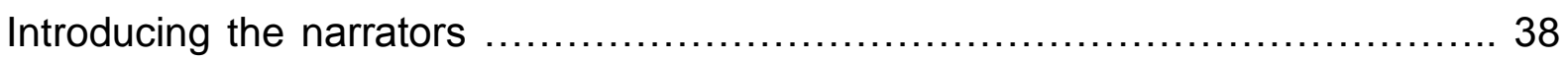

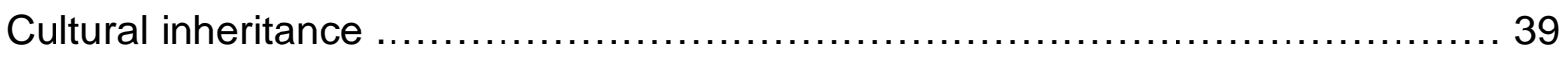

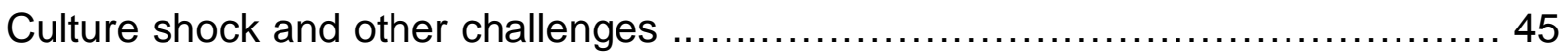

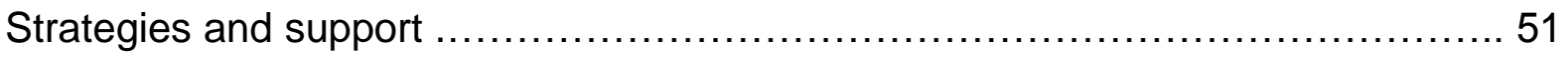

Elias and the Roman Catholic Church in New Zealand ........................... 56

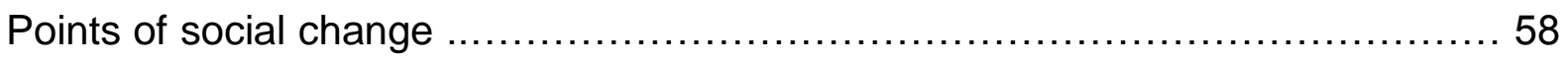

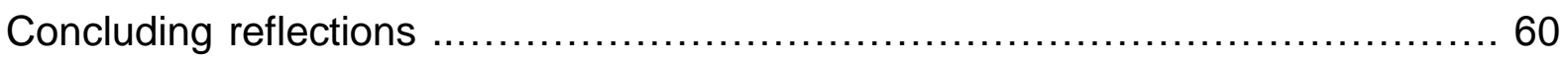

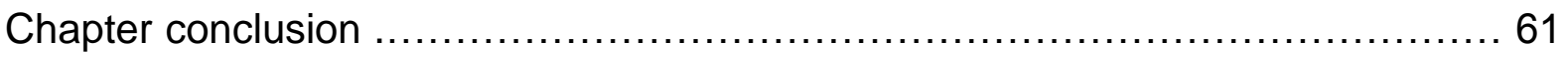

$\begin{array}{ll}\text { Thesis Conclusion } & 64\end{array}$

Reflections on the research design and methodology .............................. 64

Reflections on the research findings and process .................................. 65

Appendix A: Victoria University Ethics Approval ................................. 68

Appendix B: Participant Information Sheet …..................................... 69

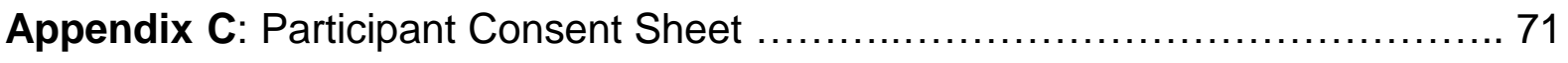

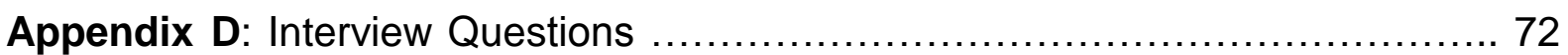

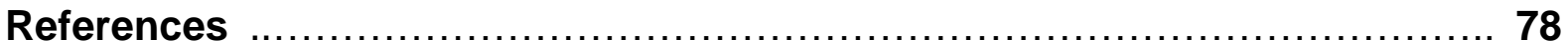




\section{LIST OF FIGURES}

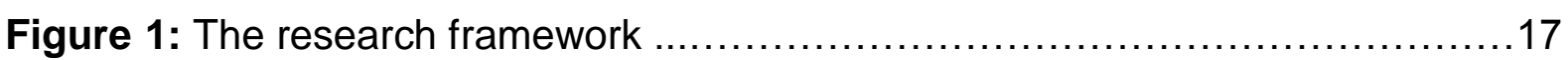

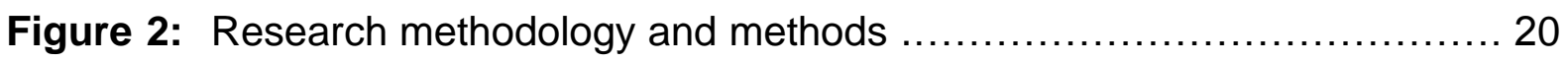




\section{Chapter One:}

\section{Introduction, Background, and Review of the Literature}

\section{Introduction}

My motivation for researching this thesis topic stems from my own family background. My paternal grandfather Joseph emigrated from Lebanon to New Zealand as a young child and became a respected member of the Wellington community. He was killed in an accident in 1964, and I never got to meet him. Although I would often hear my father talk about his father and grandparents and other Lebanese migrants who had lived in Wellington, the community was invisible to me when I was growing up. Aside from being aware that many Lebanese families had lived in the Mount Victoria area of Wellington where they had congregated around St Joseph's Catholic Church, I had very little knowledge of them.

This inspired me to design a research project which would cast some insight on the lives of Lebanese people in Wellington in the 1950s, by focusing on the experiences of a person who had immigrated at that time. I wondered if such a person would still be alive more than half a century later, and whether it would be possible to explore their memories. In 2006 I was fortunate to meet Lucia Arraj Stechman by chance at her place of work in Kapiti. A New Zealand born Lebanese, Lucia was interested in my research topic and agreed to ask members of her family if they would be interested in participating. Lucia's father Elias, a Maronite Catholic who had emigrated from Lebanon to Wellington in 1953, was exactly the type of participant I was looking for.

\section{Aim and objectives}

For the reasons I have outlined, the main aim of the research is to gain insight into the experiences of members of the Lebanese community in Wellington in the midtwentieth century by exploring the reflections of migrant Elias Arraj.

In order to understand more fully the impact and meaning of Elias' experiences the research objectives focus on three particular issues. The first of these objectives is to identify and explore those aspects of a cultural inheritance which continued to be important to Elias once he arrived in New Zealand. 
In particular, what customs or values did Elias consider to be fundamental to his sense of cultural identity, and how were these traditions affected by his experience of immigration and adjustment to a place of settlement? I also aim to explore the ways that Elias' Lebanese cultural identity influenced his interpretation of his experiences in Wellington.

The second objective is to explore the key challenges, difficulties, and obstacles that Elias faced when adjusting as a new migrant in Wellington. Did he have any access to formal social or financial support to ease the adjustments of resettlement? How did he adapt to his new environment and what were the successes and surprises?

The third and final objective is to explore the links between Elias' cultural identity and his affiliation with both the Maronite Church in Lebanon, and the Roman Catholic Church in New Zealand. How did Elias' association with the Roman Catholic Church affect his experience of adjustment and re-settlement in Wellington?

It is my aim that the research will contribute to the creation of an archival resource about the experience of the Lebanese in Wellington for the benefit of members of the immigrant community and their descendants. The academic value of the research is its contribution to an understanding of migrant experience in New Zealand. The findings have the potential to achieve insights into some of the ways that the social character of Wellington was perceived by a newcomer with a different social and cultural perspective. This may in turn draw attention to ways in which the ethnic and cultural differences of newcomers were tolerated, supported, or undermined in midtwentieth century New Zealand.

\section{Overview of the research design}

The research design employs a constructionist framework and the reasons for its application are explained in detail in Chapter Two. The research is designed to work inductively, aiming to achieve critical insights - critical in the sense that social knowledge takes into account the relationship between power and culture by investigating 'given' values and assumptions. This orientation enables me to consider for example, Elias' access to support networks or employment in Wellington. 
A secondary data collection method involves the thematic analysis of an archive of oral histories lodged with the Alexander Turnbull Library. This archive, comprising the oral histories of some members of the Lebanese community in Dunedin, is a rich source of background and context for the primary interviews with Elias. The results of this analysis have the potential to add depth to the findings relating to enduring aspects of Lebanese traditions and culture.

\section{Scope and limitations}

The primary data collection method involves an in-depth exploration of one participant's unique experience, and this has implications for the research.

Although some of Elias' experiences and memories will reflect similar aspects of the experience of others, this research does not claim to account for the migrant experience of the Lebanese community as a whole. For example, the experience of women and children could be expected to be very different to that of Elias', as could the perspective of migrants who identified with religious denominations outside of the Maronite faith.

The scope of the research does not include an in-depth investigation into Lebanese politics or history. Although the research does not entail a detailed study of immigration or assimilation theory, the discussion does include references to concepts and terms which are commonly used by researchers aiming to describe migrant experience. The next section of this chapter will therefore commence with a brief overview of these constructions and the way they are employed in the discussion which follows.

\section{Background}

\section{Terms and concepts}

The term ethnicity will be used to refer to persons and communities with a: 'shared language and culture, descent, religion, nationality, and separateness due to disadvantage or discrimination' (Martin, cited in Beaglehole, 1990:9). Other terms which are often used interchangeably by researchers aiming to differentiate between immigrant groups and a host community in a place of settlement include: ethnic 
identity, cultural heritage, or cultural identity, and these will also feature in the discussion.

In very broad terms the term assimilation is often used to describe a process of integration experienced by migrants in a host country. Many researchers use assimilation to describe a 'process' of social merging which involves the erosion of the 'differences' of an immigrant person from those of the mainstream or host group (Trlin, 1979:184; Friedman, 2003:1). Garlough (2003:1-2) defines the term as a process 'by which people who do not have a common cultural heritage come to share the same body of opinions, traditions, and allegiances'. Beaglehole (1990: 255) makes an important distinction between 'external assimilation' on the one hand '[which is] concerned with behaviour regarding food language, and lifestyle, social contacts, outlook and attitudes [and] internal assimilation... refer[ring] to [the] psychological identification and perception of migrants'. This distinction is important because it allows the researcher to consider ethnicity and assimilation in both collective and individual terms.

The work of researchers such as Hareven (1996:254) challenges the validity of using the term assimilation to imply that such a process is an inevitable or desirable. Indeed some researchers refute the existence of such a process at all. Garlough (2003:2) for example suggests:

...some scholars argue that...assimilation never happened...Rather, the melting-pot myth emerged from the need to pressure immigrants into the white Anglo-Saxon Protestant cultural mainstream.

The concept of chain migration (MacDonald, cited in Trlin, 1979:33) refers to: ...that movement in which prospective migrants learn of opportunities, are provided with transportation and have initial accommodation and employment arranged by means of primary social relationships with previous migrants.

The term multiphase immigration describes the migration patterns of family groups. Migration was often undertaken in stages with some family members leaving their country of origin while others stayed behind. Commonly, those who migrated first would seek accommodation and employment before being joined by other family members - a process which could take some years (Garlough, 2003:1). Such delays often had the potential to de-stabilise family life by fragmenting traditional family structures and damaging relationships. 
Culture shock is often used to describe 'the impact of a totally new culture upon a newcomer' (Berger, 1963: 23). This trauma is often linked to a disparity between the expectations of migrants and the reality of their experience in a place of settlement.

Aiming for an historical, social, and cultural context for Elias' experience of immigration and re-settlement in Wellington, the next section of this chapter provides a brief overview of Lebanon focusing in particular on the way literature which has attempted to define what is meant by 'a Lebanese cultural identity'.

\section{Lebanon}

Aspects of the geography, demography, and social organisation of Lebanon in the 1950s are presented in order to explore, in the case of a new migrant such as Elias, the complex relationship between a person's sense of cultural heritage or identity, and their experience of immigration.

In 1950 the republic of Lebanon consisted of 4000 square miles of alternating mountains and plains situated between the Mediterranean Sea and the deserts of Syria and Arabia, and included five geographically defined regions: Beirut, North Lebanon, South Lebanon, Bekaa and Mount Lebanon (Hitti, 1957; Mirepoix, 1969; Ziadeh, 1957). The Lebanese population of approximately 1.4 million belonged to various religious communities or 'sects' defined by Lebanese anthropologist Khuri as 'a geographically compact group, which maintains...social control outside the sphere of the central authority' (Cobban, 1985:15).

The Maronite Catholic community with which Elias identified was recognised as the largest and most powerful of the religious sects in mid-twentieth century Lebanon. The remaining dominant sects were from greatest to least in population numbers: Sunni Muslims, Shi'ite Muslims, Greek Orthodox, Greek Catholics and Druzes (Gilmour, 1983:21). The origins of the Maronite sect are generally attributed to the Christian tribes of 'Aramaic' origin who clashed with the religious orthodoxy of the Byzantine Empire over the Monoethelite Doctrine ${ }^{1}$ and sought refuge in the Lebanese mountains.

\footnotetext{
${ }^{1}$ The description 'Maronite' was first used to describe the followers of St Maron, a $5^{\text {th }}$ Century Syriac Christian monk, and this sect accepted the 'Monotheist Doctrine' a principle which affirmed that Christ had two natures [divine and human] but only a single divine will' (Gilmour, 1983:22).
} 
The Maronites have been described in literature as an independent, proud, and ethnically unified community with a tradition of resistance to centrally organised governments, and a very strong attachment to their Church (Cobban, 1985:17; Gilmour, 1983:22; Zamir, 1985:5-6). It is important to note that Lebanese Maronites recognised the authority of the Roman Catholic Pope and were included under the auspices of the Roman Catholic Church. ${ }^{2}$

While the complex history and politics of Lebanon is outside the scope of this thesis, it needs to be acknowledged that Lebanese people identified with their own religious sect usually concentrated within a village or specific geographical region. In this way a Lebanese person would not necessarily have perceived themselves as being 'Lebanese' but would more accurately identify as, for example 'Maronite Christian' or 'Sunni Muslim' according to their religious affiliation, historical and geographic origins (Gilmour, 1983; Hitti, 1957; Ziadeh, 1957). These religious communities or sects were independent, and in the case of the Maronite Christians, geographically isolated. The autonomous character of these groups and the effect of centuries of political instability in the region meant that the central government of Lebanon was relatively weak. Political offices were divided up amongst the sects according to their relative population and influence. ${ }^{3}$

Within these religious communities or sects, social infrastructure and support for members was traditionally provided by extended family networks, rather than the state. The large extended family units that were characteristic of Lebanese social organisation within religious communities are often referred to as 'clans' (Scott. D, 2002:17). These family groups or clans were organised according to a patriarchal structure, and women were expected to conform to customs of early marriage, home and children (Sanders, cited in Akoorie, 2007:768). Most businesses were family owned and operated, and family members worked and lived in close proximity, as Gilmour (1983:14) observed:

A Lebanese would know all his relations, even distant ones, would see them often and would know everything about them. He could count on elderly relatives to find

\footnotetext{
${ }^{2}$ The union of the Maronite and Roman Catholic Church was realised in 1182 and in 1215 the Maronite Patriarch was included in the fourth Lateran council (Kayal, 1973: 409; Edde, 2000: 910).

${ }^{3}$ Lebanese political posts are distributed among the sects according to their proportion of the population. This practise is often referred to as confessionalism (Gilmour, 1983: 28).
} 
him a job, probably in a family firm or business. If he was rich, he would take it upon himself to provide for poorer relations, and would even invite them to live with him.

In summary, the literature suggests that Lebanon in 1950 could best be described as a collection of different religious communities defined by geographical limits. As a Maronite, Elias was born into a self-governing community whose members had a strong sense of their identity, origins and traditions. The next section of this chapter briefly describes the migration of Maronite people to destinations such as New Zealand.

\section{From Lebanon to New Zealand}

By 1891, the first Lebanese families had arrived in New Zealand and by 1914, as much as one quarter ${ }^{4}$ of Lebanon's Maronite population had migrated to other places of settlement (Akoorie, 2007:763; Hitti, 1957:475). Poverty, unemployment, and the need for political or religious asylum have all been identified as factors which influenced migration from Lebanon. Literature on the subject suggests migrants were usually motivated for more than one reason. Akoorie (2007: 763) described these as 'push and pull' factors; meaning that the negative conditions in countries of origin, together with the attractive prospects of host countries worked together to influence the decisions of migrants. Sanders (1980) and Akoorie (2007) agree that chain migration was the pattern for most of the migration from Lebanon to destinations such as New Zealand and newspaper references tend to support this pattern in Wellington. ${ }^{5}$

Lebanese migrants formed communities in Auckland, Wellington, and Dunedin and also in smaller centres including the Wairarapa and Palmerston North. As Akoorie (2007:764) noted, the lack of existing records was partly due to the fact that 'the Lebanese in New Zealand were religiously and geographically diverse'. Because Lebanon was not recognised as a separate country until 1946, the birthplace of Lebanese migrants was often recorded as 'Syria' on official documents and accurate census information on the Lebanese was unreliable at this time (Akoorie, 2007:764).

\footnotetext{
${ }^{4} 100,000$ people (Gilmour, 1983:28).

${ }^{5}$ With reference to the Harach family of Wellington: 'The first family member [of Constantin's family] emigrated from Lebanon in the early 1900s, opening a hair salon in Wellington's Cuba St. He [Constantin's great uncle, name unknown] returned home [to Lebanon] on many occasions, telling tales of his new country. Soon other members of the family came over...' (Evening Post, 1992).
} 
This explains the surprisingly low figure of 204 Lebanese-born residents in New Zealand which was recorded in the 1951 census (Veitch and Tinawi, 2006:211). The percentage of 'non-British' migrants in New Zealand in 1956 was relatively small; Beaglehole (1990:13) suggests it was 2.18 percent of the total population.

\section{Review of the literature}

'...persons of Lebanese descent...[are] physically and culturally so much akin to the white New Zealand population that they are hardly visible' (Taher, 1970:38).

New Zealand researchers such as Beaglehole (1990:9) have drawn attention to the large volume of material which explores aspects of immigration, re-settlement, and ethnicity. However, as Akoorie (2007:763) points out, there has been a significant gap in information about the Lebanese migrant community in New Zealand. My own inquiry suggests that very little is known about the Lebanese in Wellington in the mid-twentieth century. With a few exceptions, the scholarship and literature that does explore the experience of the Lebanese in New Zealand tended to focus on two main themes, the first is the extent to which the Lebanese have been assimilated in New Zealand. The second theme is concerned with documenting the success of Lebanese who have achieved considerable recognition in business and public life.

Consistent with the theme of 'assimilation', Thornton's (1968:5-6) comparative study of the Chinese, Dutch and Lebanese communities in New Zealand sought to 'understand...the factors which both inhibit and facilitate the assimilation of ethnic minority communities into the host population' while assessing the 'place of ethnic groups in a New Zealand urban setting'. Sanders (1980:1) argued that the Lebanese community was:

...worthy of special interest [partly] because of its long association with Dunedin, the remarkable social and economic success achieved by some of its members and the way it has adapted to the host society.

Focusing on the cultural identity of second and third generation Lebanese New Zealanders, Farry (2000:ii-iii) on the other hand, argued against 'outmoded essentialist and homogenous representations of national culture and identity'.

Literature which relates to the experience of Lebanese migrants in New Zealand centres other than Dunedin also tends to focus on relating success and accomplishments. McGill (1982) for example, devoted most of his chapter on 
Lebanese migrants to documenting the achievements of the Corban family. Referring to some members of the Wellington Lebanese community, McGill (1982:111) described them as '... [well] known in broadcasting circles'. Scott (2002:7) introduced 'A Stake in the Country' by pointing out that the Corban family name 'to many New Zealanders is synonymous with wine'. 'Peanuts and Pictures' (Moodabe, 2000 ) is another example of literature which documented the achievements of a wellknown Lebanese family - in this case the Moodabes, who founded the Amalgamated Cinema chain in Auckland. While providing a comprehensive historical account of Lebanese migrants in a New Zealand socio-economic context, Akoorie (2007) also explored the case histories of New Zealand's most successful Lebanese entrepreneurs.

Biographies of well known Lebanese men and women are featured on the website of Te Ara: The Encyclopedia of New Zealand, together with some general information about the migrant community in New Zealand. The Bouzaids are one of many New Zealand Lebanese families who have made the private history of their migrant grandparents accessible to a wider public. In their case, the personal diary of George Bouzaid who died in 1933, was discovered in a Wairarapa house and translated from Arabic into English in $1992 .{ }^{6}$ In addition to these main sources, the occasional reference to Lebanese immigrants can also be found in newspaper articles, ${ }^{7}$ and obituaries.

Specific to the Lebanese Dunedin community, the history of the well-known Farry family was co-authored by Page and Farry (1990). McDonald compiled a pictorial history of the Lebanese in Otago and Southland which was published in 2004. The website of the Cedars of Lebanon Club is a valuable source of historical information about the Dunedin Lebanese and also includes autobiographies of some of its members.

Literature on the perspectives of other migrant groups assisted with my understanding of the social and cultural character of New Zealand as a destination for migrants in the 1950s. In terms of the effect of push and pull factors which influenced other migrants of other destinations, Hutching (1999:81) found that 'by far

\footnotetext{
${ }^{6}$ The Bouzaid family also has a website, see references.

${ }^{7}$ Such as for example, the reference to the Harach family, see footnote on previous page.
} 
the greatest influences on [British] immigrants... were [the positive] reports from friends or relatives who had already emigrated to New Zealand'. De Bres (1997:4) suggested that the expectations of Dutch migrants were heightened due to the way 'New Zealand marketed itself [during the 1950s] to the potential migrants it needed to boost its workforce' and Hutching (1999:81) found examples of advertising used on buses in Britain which represented New Zealand as 'the land of golden opportunities for ambitious men and women'.

Beaglehole's research (1990:151) suggested that new migrants perceived New Zealand as a 'British' country. De Bres (1997:3) pointed out that new arrivals from non-British origins were socialised by an education system which taught them to regard England as 'home' and names were anglicised - sometimes against the wishes of migrants. Despite New Zealand being perceived in these terms by migrants from other origins, Phillips (2006:39) noted many instances when British migrants also 'encountered a surprising hostility to 'Poms' (the slightly derogatory term used for British immigrants)'.

Also reflected in much of the literature on the Lebanese that has been discussed, researchers have argued that assimilationist immigration policies adopted in New Zealand in the 1950s actively promoted the 'ideal' of an ethnically homogenous British society. The assisted immigration scheme of 1947 which favoured British immigrants was cited as evidence of this (Masgoret \& Ward, 2006:1). What is more, Ongley and Pearson (1995:773) pointed out that because of its relatively small labour requirements the homogeneity of the New Zealand population was even more noticeable than those of its much larger neighbour Australia, or Canada.

Reflecting on his own experience of migrating to New Zealand as a child, de Bres (1997:1) suggested that in the 1950s 'assimilation was the official culture' and likened the re-settlement of migrants to the form of closed 'adoptions' practised at the time, 'The Government called us "new New Zealanders"...and we bought into it...forget your past, your other identity, you're one of us now'.

Indeed Doornbos (2006:39) went as far as to suggest that government policy deliberately prevented the formation of geographically concentrated migrant communities. 
Adopting a critical approach - in this sense considering dominative social relationships - Hareven (1996:254) explored the historical tendency of a larger host society to try to 'mould the identity of different ethnic groups in its own image'. New Zealand researchers such as Božić-Vrbančić (2008:98) have also suggested that such assimilationist policies functioned to promote the interests of majority ethnic groups.

Researchers such as Beaglehole (1990: 16-21) related the impressions of new migrants who described New Zealand as a 'drab' and 'grey' society dominated by a 'Christian' or 'Puritan' ethic. Beaglehole (1990:13,21) also found that migrants commonly experienced pressure to conform to 'New Zealand ways' which included restrictions on shopping hours, and entertainment on Sundays. Doornbos (2006:39) described what immigrants viewed as the 'abnormal attitudes' of New Zealanders with respect to socialising and alcohol consumption. New Zealand food was described as bland and unappealing, and migrants sought out more variety; de Bres (1997:2) for example, described a delicatessen in Wellington which supplied no less than six different ethnic communities but had no 'local' customers.

The literature suggests that New Zealanders were resistant to the idea of ethnic and cultural diversity of migrants, and as Beaglehole (1990:13) pointed out 'what is very often revealed is...the suspicion of New Zealanders about people who are culturally different'. Not all researchers agreed that the New Zealand social climate of the 1950s was inhospitable to the differences of migrants. Exploring the experience of members of the Chinese community for example, Manying Ip $(1996: 15,25)$ argued the wider New Zealand became more welcoming to migrants because of changes in its previously 'anti-Chinese' government policy:

The...fifties...were New Zealand's years of tolerance and generosity....there was a general acceptance of people from other cultures. Chinese [refugee] children experienced far less overt racism [than in previous years].

Considering the experience of Gujarati migrants in Wellington, Kasanji (1982:iii) argued that the nature of the differences of migrants; and whether such differences were perceived visually, affected the way migrants were treated by the host community. 
In Dunedin as Veitch and Tinawi (2006:209) pointed out, Lebanese migrants were visually different from other New Zealanders because their attention to grooming, dress, and jewellery set them apart. Akoorie (2007:777) argued that such differences were perceived negatively by their New Zealand hosts, 'Since they [the Lebanese] were seen to be different it was assumed that they were worse than other New Zealanders'.

Migrants, as Trlin (1979:8) reflected, bring with them 'a set of mature social, economic and political values developed in...[their] homeland'. Akoorie (2007:777) described the cultural values of Lebanese migrants in New Zealand in this way:

They [the Lebanese] viewed society as a collection of autonomous individuals linked by social contract, the heart of which was the extended family and the religious affiliation to which they belonged.

Hitti (1957:476) argued that a strong sense of cultural ethnic identity assisted Lebanese migrants with the process of adjustment and re-settlement in host countries:

[The Lebanese] had no insurmountable difficulty in acquiring the feeling of 'at homeness' wherever they went. Their versatility and adaptability helped them become 'all things to all men'...in Egypt they became Egyptians.... while at home they thought of themselves as Maronites.

McGill's claim (1982:110) that 'The Lebanese glided effortlessly into the business and professional echelons of New Zealand society' was rejected by Akoorie (2007: 777) who argued that historical evidence suggests that Lebanese migrants were discriminated against by other social groups who regarded them as 'disreputable vagabonds'. Despite their strong sense of cultural identity, this prejudice was inevitably one of the practical challenges faced by Lebanese migrants on their arrival in New Zealand.

A great deal of the literature on the experience of migrants in the Twentieth Century explores the phenomena of culture shock and explanations for it. As Berger (1963:23) pointed out, the first experience of a new environment was often traumatic for immigrants who had high expectations of a place of settlement. Scuro (2004:13) described this disruption in terms of 'the wrenching impact of immigration on culture' attributed in part, to a clash between the preconceptions held by migrants and the reality they faced. 
New Zealand researchers have also documented many accounts of culture shock and explored the reasons for it. Beaglehole described (1988:31-33) the disappointed expectations of one new arrival who was 'unsure now what his expectations were but...had hoped that a city the size of Wellington would have basic amenities. The...absence [of these amenities]...was a shock'. Doornbos (2006:39) conveyed the distress of Dutch immigrants: 'To end up in a tatty little town instead of a city [in European terms] was a great shock. The timber, tin roofed houses looked impermanent'.

Researchers have found that the effects of culture shock were compounded by the disruption of family relationships and the loss of traditional support networks. Migrants who left family members behind in their home countries as a result of multiphase immigration were particularly vulnerable to what Garlough (2003:1) called the 'fragmentation' of family life.' Scuro (2004:11) described this fracture from the perspective of a migrant for whom "America represented...the "mutilation" of the family left in Italy, with the inevitable consequence of a feeling of complete estrangement [for the migrant]'. A similar sense of distress at the loss of family relationships was captured in the foreword of the translated diary of Lebanese migrant George Bouzaid. Marilyn Bouzaid (1992) said:

Throughout the diary we experience the conflict which existed in George's mind between the desire to migrate and make a better life for himself and his family, and his close ties to his homeland and particularly to his father. He never quite seemed to reconcile these two...

The disruption of family and kinship networks had the potential to lead to distress and social dysfunction among migrants. Trlin (1979:215) for example, described this in terms of 'disorders of thought and behaviour' suffered by migrants which had the potential to lead to 'delinquency, crime, alcohol and drug abuse'.

New Zealand researchers have considered strategies that migrants adopted to help alleviate the negative effects of culture shock and try to compensate for the loss of family relationships in their new environment.

O'Shea Miles (2004:82) found that a community of Irish migrants received support from their Church, Irish Catholic priests would provide social welfare services such as arranging for the fostering of children and administering to the sick. This contributed to a process whereby as O'Shea Miles (2004:81) suggested, the 'cultural 
affiliation' of an Irish migrant community 'became indistinguishable from [its] religious affiliation'. Similarly, Akoorie (2007:774) also noted that the social support networks of Lebanese migrants were strengthened by their collective affiliation to a church community. In the case of the Lebanese community in Wellington, I understood there had been a number of Lebanese families who congregated around St Joseph's Church in Mount Victoria in the mid-twentieth century. ${ }^{8}$ It was therefore surprising that despite the inclusion of a chapter on immigrant parishioners there is no mention of the Lebanese in Duggan's (2007:347) archive of church events.

Garlough (2003:2) pointed out that 'immigrants depend on community networks to ease the pain of culture shock'. Lebanese migrants also established ethnic clubs as McGill (1982:112) noted 'The Lebanese...are mainly found in Auckland, Wellington and Dunedin, and each has a Lebanese social club'. Trlin (1979:163) found that such ethnic associations were not always welcomed in New Zealand:

...immigrant...associations are typically viewed with suspicion. With few exceptions they are often seen by members of the host society as obstacles to acculturation...they may even be perceived as threats to national security that warrant close surveillance if not declared illegal and closed down.

Employment opportunities also provided a sense of structure and support for migrants in New Zealand. Trlin (1979:13) found that Croats were often drawn to small independent businesses such as food retailing, catering and wine-making. Such opportunities provided employment and economic advancement for large extended families and did not require migrants to have the high level of proficiency with the English language or education required for more 'professional' career options.

The literature suggests that Lebanese migrants traditionally sought out selfemployment, or small family business opportunities. Hitti (1957:475) for example, described the way Lebanese migrants chose hawking ${ }^{9}$ in places of settlement in order to finance the establishment of small-goods stores. Various sources briefly mention the small-scale businesses which were established by Lebanese migrants in

\footnotetext{
${ }^{8}$ Lebanese of St Joseph's congregation included at one time, my own grandfather and other members of his immediate family.

${ }^{9}$ Hawking describes self-employment which involved Lebanese in peddling small goods such as trinkets, articles used in sewing, trinkets and jewellery, and toiletries. Hawkers would travel door to door in rural areas of New Zealand, carrying their wares in suitcases or carts (See Veitch and Tinawi, 2006:209).
} 
Wellington from very early in the Twentieth Century: these included hairdressers, general goods and clothes shops (Evening Post, 1992; Veitch and Tinawi, 2006:209). McGill (1982:108) suggested that these family owned and operated businesses were 'built up' with the earnings the Lebanese received from hawking in New Zealand's isolated communities. A few Lebanese women were also successful entrepreneurs in New Zealand; for example, Sherifie Coory's 'enthusiasm for commerce' resulted in astute business and property investments (Page, Te Ara:2010). Exploring the considerable entrepreneurial successes of the Lebanese despite their relatively small numbers, Akoorie (2007:776) found that migrants 'relied heavily on the reciprocal obligations of families' which was an integral part of a shared sense of their Lebanese cultural identity. Lebanese migrants would be 'under an obligation' to work for the extended family members in New Zealand who had arranged their immigration (Akoorie, 2007:774). Migrants were able to grow their businesses by mobilising 'social capital' in the form of 'price discounts' or 'interestfree loans' and in this way robust family networks and 'social structures' were ‘embedded' with 'economic action' (Akoorie, 2007:775).

Considering the experience of Chinese migrants in the mid-twentieth century Manying Ip (1996: 73) identified a sense of nostalgia surrounding the concept of a family workplace; suggesting the image of a small family-owned business was not borne out by the reality of being self-employed which included 'long hours' and 'physical hardship'. One of the disadvantages of this type of employment was the potential isolation of migrants from a wider New Zealand community resulting in their social marginalisation. On the other hand, Manying Ip (1996:59) pointed out that one of the benefits of self-employment was that such family businesses 'spared' migrants from 'having to compete with mainstream New Zealanders' for limited jobs.

Literature which described Lebanese migrants in New Zealand often contextualised their experience within a process of assimilation. For example Veitch and Tinawi (2009:2) pointed out that 'Lebanese have been called the quiet immigrants because they were easily assimilated into New Zealand society'. ${ }^{10}$ The validity of describing the adjustment of immigrants in terms of assimilation has been challenged by New Zealand researchers. O'Shea Miles (2004:87) for example, found that a strong

\footnotetext{
${ }^{10}$ This differs from a similar statement made by Veitch and Tinawi in an earlier publication (2006:208) which reads: 'They [the Lebanese] were called "the quiet immigrants", because they worked hard to establish themselves'.
} 
sense of cultural identity was retained by Irish migrants and 'transmitted [from one generation to another] through family, kinship and community' and Beaglehole (1990:158) argued that a migrant's ethnic identity, cultural differences, and social practices continued even when a person was isolated from their ethnic community in a place of settlement. In the case of Lebanese migrants in New Zealand, Akoorie (2007:774) found that historical social networks and family obligations were reconstructed as they had existed in Lebanon, and that family members were 'linked to one another by residential proximity, occupational pursuits and church activities'.

Despite the lack of scholarship on the experience of Lebanese in Wellington in the mid-twentieth century, this review has drawn attention to some of the issues that faced a migrant at this time. Motivated by negative factors at home and positive reports about host countries, migrants often faced considerable difficulties on their arrival in New Zealand. Obstacles to adjustment and re-settlement included the culture shock of a new environment, and trauma from the disruption of family relationships and support networks. Assimilationist politics permeated all aspects of social life in New Zealand, and migrants felt they were expected to forget their ethnic or cultural differences and conform to the behaviour norms of the majority.

Traditionally Lebanese Maronites lived with other members of their extended families in independent communities defined by religious affiliation. Their closely linked social structure was reconstructed in New Zealand and resulted in entrepreneurial success for many families. Family obligations with regards to employment were honoured in New Zealand as they had been in Lebanon, and social and support networks were strengthened by the geographical closeness of family groups, membership of a church community, and the establishment of ethnic clubs. Together with the question of the assimilation of the Lebanese, the success of this group in business and public life tends to be the primary focus of much of the literature on the Lebanese migrant community in New Zealand. This raises questions about the experience of Lebanese migrants who did not assimilate or achieve public recognition in business or public life. Before considering the experience of Elias, the following chapter will explore aspects of the research design which was implemented in the method. 


\section{Chapter Two: Research Design and Methodology}

Human experience is complex and requires a research framework that allows data to be interpreted within its social context. Aiming for new insights, this research design employs a constructionist epistemology and a critical theoretical approach. The methodology of narrative inquiry involving the collection of primary and secondary data employs the methods of in-depth interviews and an analysis of archived oral histories. The components of this research design and their theoretical implications are examined in this chapter followed by a critically reflexive exploration of ethical considerations: protocols and issues, the implementation of the research methods, and the process of data analysis.

\section{The research framework}

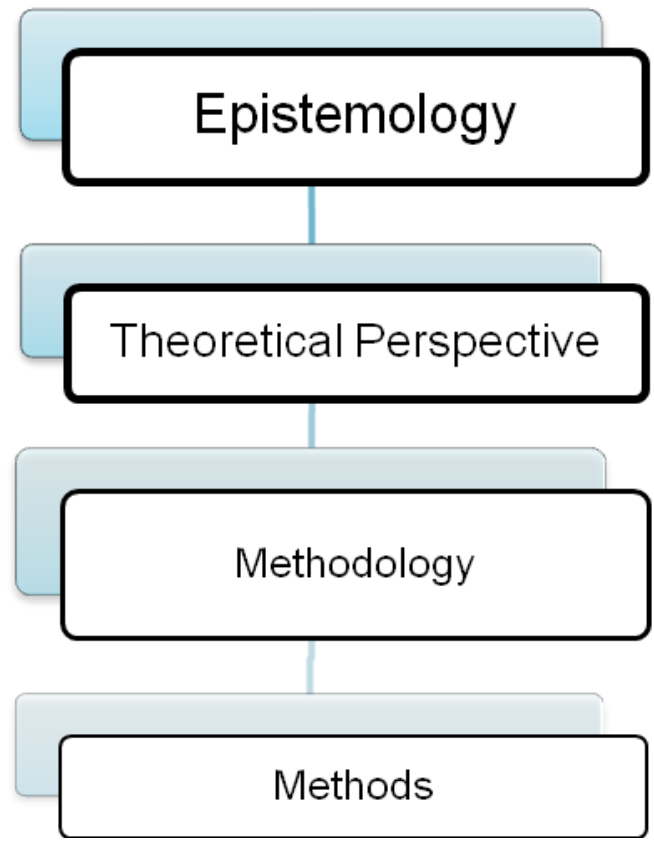

Figure 1. The research framework

The research was designed using Crotty's four element model which defines epistemology as 'the theory of knowledge embedded in the theoretical perspective and thereby in the methodology' (Crotty, 1998:3). As shown in Figure 1, the researcher's epistemological assumptions inform the research process at every stage. The discussion of the research framework will therefore begin with an exploration of the constructionist epistemology which informs this research. 


\section{Research epistemology}

A constructionist epistemology ascribes meaning in relation to human consciousness. As Crotty (1998:43) explains 'meanings are constructed by human beings as they engage with the world they are interpreting'. From this perspective, meaning does not exist independently of awareness or experience. Aligning the research with a constructionist understanding of knowledge allows the researcher to consider the influence of both external socio-historic events and processes as they affect and are interpreted by both collective and individual social consciousness. In this way constructionist researchers are able to explore the complex relationship between an individual and their social world and the ways this relationship shapes and is reflected by individual values, beliefs, and emotional responses. Embedded in a constructionist epistemology is the ability to consider the unique way individuals make meaning of experience (Crotty, 1998:58). Accordingly, constructionist oriented research maximises the potential for critical insight into human experience; critical in this sense meaning that it allows for the exploration of a person's underlying cultural values and assumptions.

When considering this research design, both objectivist and subjectivist epistemologies were deemed to be incompatible with the research aim. The limitation of an objectivist epistemology is that it is embedded in the idea that truth and meaning exist independently of human perception. In other words, an objective truth or meaning is discovered rather than constructed. The shortcomings of this epistemological position become apparent when considering migrant experience. For example, objective research cannot offer insight into a migrant's views, beliefs and emotions which, according to a constructionist understanding of meaning are created during a person's engagement with their social world.

A subjectivist orientation was also rejected for this project because it too was unable to explore human experience as it is shaped by or reflects meaningful socio-historic processes and cultural realities. From a subjectivist standpoint meaning is imposed by the subject on the object rather than being the outcome of a relationship between the subject and the object (Crotty, 1998:9). Thus the shortcomings of a subjectivist approach for this research include its inability to capture the importance of factors which are external to an individual. 
For example, subjectivist research may fail to consider the relationship between migrant experience and the responses of host communities, and the impact of unfamiliar social and cultural practices on an individual.

\section{Critical theoretical approach}

A critical theoretical perspective informs this research in several ways. In the first instance this approach provides a valuable research tool for exploring the social realities of individuals who identify with ethnic minorities in society. The social worlds of migrant groups and their interaction with dominant groups in host societies involve power relations and, as Crotty (1998:158) explains, 'of obvious and, indeed, primary concern to critical theorists are dominative relationships'. In short, critical theory illuminates the relationship between power and culture.

By adopting a critical perspective, the researcher may consider a wide range of cultural factors and issues which influence the experience of migrants and their interaction with a host community. These may include access to employment or social support networks in a place of settlement. Additionally, a critical approach is able to explore any given social reality through examining 'commonly held values and assumptions, challenging conventional social structures, and engaging in social action' (Crotty, 1998:157). Employed in this way, a critical theoretical perspective has the potential to achieve new insights into the meaning of migrant experience in both a collective and individual sense.

The critical perspective adopted in this research also concerns itself with points of social change. As O'Brien (1993:9) argues, critical researchers:

...want to know at what points and in which events social change is imminent. They want to know this because they want to see beyond or outside of our present social arrangements. 


\section{Narrative inquiry}

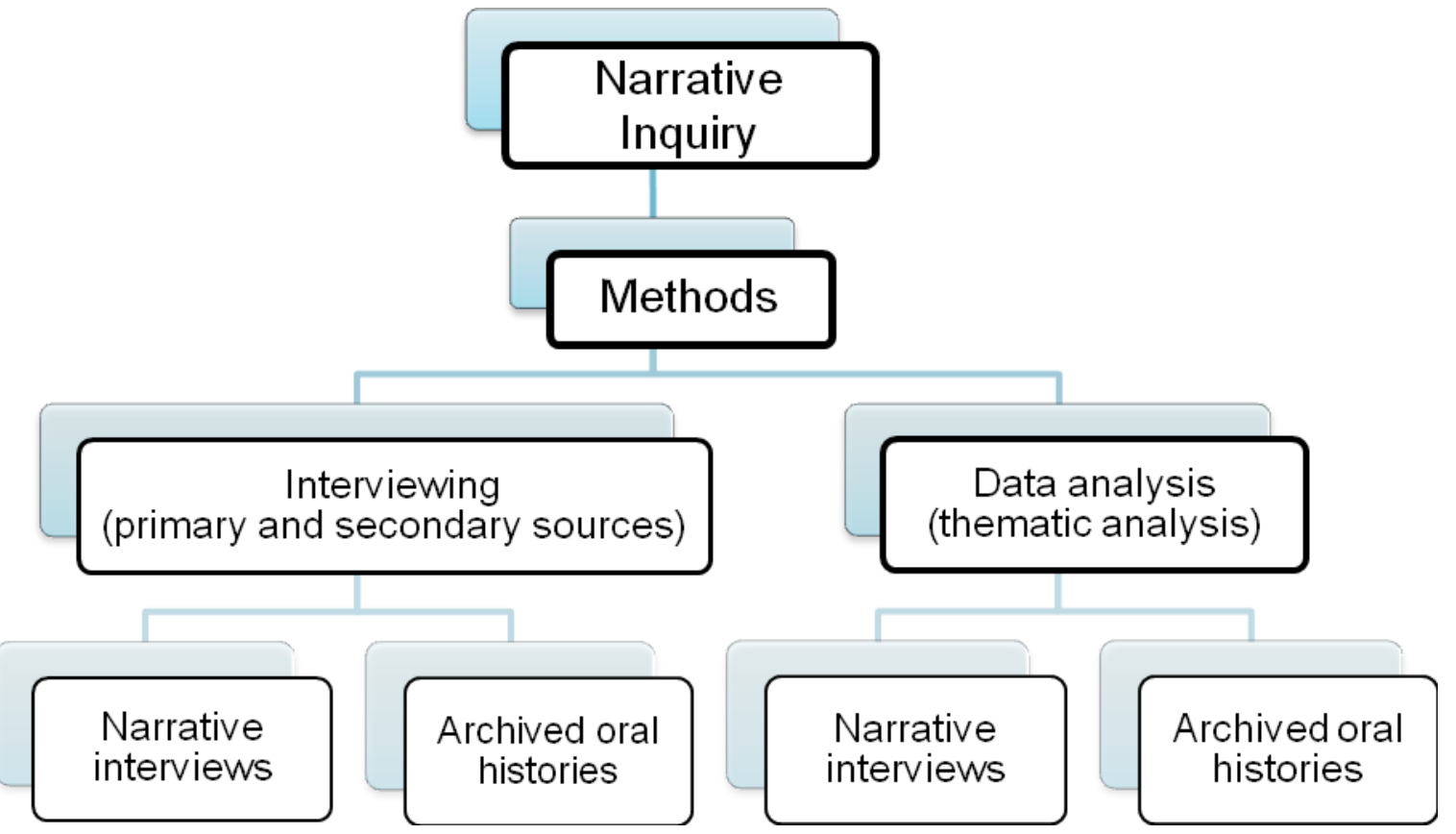

Figure 2. Research methodology and methods

The research methodology was designed to work inductively, that is, it was intended that the inquiry should begin with specific observations about the phenomena being investigated which would lead to the identification and understanding of general patterns (Patton, 2002:55-6). This inductive strategy calls for the use of qualitative methods in contrast with a deductive approach employing quantitative methods which as Kelly (2010:130) explains identify 'possible relationships between variables...before data collection starts'.

Reflecting the constructionist epistemology and critical theoretical approach, narrative inquiry refers to the collection and presentation of stories of the experience of participants with the aim of bringing the voices of the participant closer to the reader (Grbic, 2004:83). Narrative inquiry requires the researcher to be critically reflexive in that the researcher is expected to recognise and reflect on their own place in the construction of knowledge. Consequently, one of the strength of this methodology is the transparency it lends to the research.

Narrative inquiry informs the 'case-centred' orientation of this research. A 'case' involves the 'unique aspects' of 'an individual, family, community, group, organisation or other unit of social life' (Riessman, 1993:80). 
This research involves two case studies: the first being the documentation of the experiences of a Lebanese migrant in New Zealand, while the second draws on oral histories lodged with the Alexander Turnbull Library.

One of the benefits of employing a case-orientated methodology is that it offers constructionist researchers an opportunity to acknowledge and explore both the historical context and the social processes which affect individual experience, as well as the reflections, beliefs, cultural values, memories, feelings and impressions of an individual or a group of participants. In this way narrative inquiry accords participants what Mishler (cited in, Riessman, 1993:80) observes to be 'unity and coherence through time, respecting them as subjects with both histories and intentions'.

As shown in Figure 2, the data collection and interpretation components of the research design involve both primary and secondary sources. Primary research refers to the data collected by the researcher to satisfy the research question, aim and objectives. Secondary data sources involve existing material which in this instance was collected by other researchers for other purposes.

\section{Interviewing}

Reflecting the constructionist orientation of the research design with its emphasis on the generation and transmission of meaning, the primary method of data collection is the recording of narrative interviews. Interviewing methods record the responses of a participant or group to the questions and/or prompting and probing of a researcher. Interview techniques range from eliciting responses to structured set questions through to participant-led spontaneous dialogue or in-depth interviews where the aim is 'to obtain descriptions of the life of the interviewee with respect to interpreting the meaning of the described phenomena' (Kvale, 1996:5-6).

The narrative history interview as applied in this research may be understood as 'the subjective and selective process involving narrator engagement in a reflexive traverse of recollecting, reliving and reinterpreting events of the past' (Beasley, 2010:4). From a critical perspective, it is acknowledged that the interview method involves an unequal relationship between the researcher and the participant that favours the researcher (Kvale, 1996:27). 
Narrative history interviews which involve participant-lead dialogue aim to redress this imbalance by allowing the participant to 'open up the research interview', thereby requiring 'investigators to give up some control' (Riessman, 2003:1).

From a critical perspective, a particular advantage of the narrative history interview is its respect for the relevance of all 'stories' related by the participant. This feature allows the researcher opportunities to explore meaning in ways that are not possible when employing other more structured interviewing methods. As Ayres (2008:1) points out '...the content and structure of the narrative contains implied meanings that are as important to understanding the narrative as the overt meanings - and perhaps more important'. Recognising the importance of the narratives in this way allows the researcher to access meanings which often exists beneath the surface of what is being said.

Narrative interviewing is a challenging method as it requires considerable skill and attentiveness on the part of the interviewer (Kvale, 1996:145). Jack (1998:165) for example, emphasises the importance of active listening, suggesting that an interviewer must employ a 'third ear' in order to look for and identify a 'muted channel of...experience'. When this technique is implemented, this method has the potential to obtain insight into the experience of individuals or groups who may not share the perspectives of members of the dominant culture. Indeed Jack (1998:164165) argues that the narrative interview is an effective 'tool' in the hands of researchers who actively listen for features such as the participant's culturally reflexive observations and/or 'self-evaluative' statements. Such features provide valuable insight into the experience of participants as they may allow understanding 'beyond existing [culturally dominant] frameworks'. Consequently, narrative interviews are able to explore ways in which a participant may have rejected or internalised the expectations of a dominant social group and its impact on a participant's experience of cultural difference.

Further opportunities for understanding are offered by the immediacy of a narrative interview. Because this interviewing technique involves active communication between a participant and a researcher it allows open, free-flowing dialogue encouraging the researcher as Kvale (1996:149) suggests: 
'to clarify and extend the meanings of the interviewee's statements [by providing]...interpretations of what is said, which may be then be disconfirmed or confirmed by the interviewee'.

In such ways, the narrative interview has the ability to capture the quality, intensity and importance of what is being expressed.

\section{Secondary data}

Oral histories provide a rich source of secondary data. As Frisch (1990:188) points out, oral narratives are a:

...powerful tool for discovering, exploring and evaluating the nature of the process of historical memory - how people make sense of their past, how they connect individual experience and its social context, how the past becomes part of the present, and how people use it to interpret their lives and the world around them.

Explored in this research for their background and context, the inclusion of archived oral histories strengthened the research design through providing comparative historical accounts of events and personal experiences that would otherwise have been unavailable.

When considering the capacity of oral history to capture the 'historical circumstances which shaped ...[a] point of view' (Hareven, 1996:247), they not only capture something of the past but also give voice to marginalised communities or groups within a society. Indeed, Hareven (1996:248) argues that such testimonies can be 'almost the only feasible route for the retrieval of perceptions and experiences of whole groups who did not normally leave a written record'. Consequently, this secondary data source has the potential to provide 'valuable information about aspects of the past inaccessible through other written sources' (Green \& Hutching, 2004:3). Conversely, a limitation of oral histories is that they have been collected by researchers at another time and for another purpose. In other words, the researcher needs to be aware of the purpose and function of secondary material when exploring it for a new aim or objective (McCullough, 2004). 


\section{Data analysis}

In keeping with the inductive orientation of this research, a thematic analysis was employed to interpret the data generated from the narrative interviews and the secondary data from the Turnbull oral history archive. Thematic analysis is designed to identify what Patton (2002:55-6) describes as:

...categories or dimensions of analysis [that] emerge from open-ended observations as the inquirer comes to understand patterns that exist in the phenomena being investigated.

Despite the methods being case-centred, a thematic analysis can nevertheless be used to 'generate categories, theoretical concepts and observations about general processes' (Riessman, 2011:311).

Kvale (1996:178) suggests the analysis of data begins during the interview as the researcher checks the participant's meanings and through allowing the narrator 'ample freedom and time to unfold their own stories' (Kvale, 1996:130). The act of transcription marks the formal process of narrative analysis as the transcriber converts recorded material into written form. This practice can cause problems for the researcher if they fail to acknowledge what Kvale (1996:163) identifies as the 'constructive nature of transcripts', that is, the transcript as a research artefact created in response to a recorded interview. Jack (1998:169) also draws attention to aspects of an interview such as pauses, laughter, facial expressions and/or gestures that convey nuanced meanings but which are 'unavailable in a written text'.

Undertaking a thematic analysis involves the researcher in several stages of interaction with the data. Kvale (1996:190) identifies the three main stages as 'structuring', 'clarification' and 'analysis proper'. Throughout each of these stages the researcher is guided by the research aim and objectives. The object of the first two stages is to "clarify the data by editing out 'repetitions [and] distinguishing between the essential and the non-essential' aspects of the dialogue (Kvale, 1996:190). In this way the material becomes condensed and themes begin to emerge, allowing 'clumps' of relevant data to be grouped (Glesne, 2006:147). As themes emerge 'recurring patterns, topics, viewpoints, emotions, concepts [and] events' begin to appear (Bailey, 2007:153). 
Themes may also be present in various forms such as particular reflections, or simply be identified as 'a common thread that runs through the data' (Richards, 2007:135). Themes also need to be explored for possible links, overlap and interrelationships. Once the stages of structuring and clarification are completed and sections of the narrative and/or quotations have been selected to illustrate particular themes, the process of interpretation of the data begins with the aim of developing new understandings and perspectives on the research topic.

Thematic analysis involves deconstruction and re-construction of the narratives in order to identify and explore emergent themes and present them in a modified form as findings. Beasley (2010:4) identifies this process as involving restructuring, 'decontextualisation rearrangement and reconstitution'. Because each of these aspects have the potential to distort the participant's meaning the researcher has to be sensitive and empathic to the essence of what the narrator was attempting to communicate (Kvale, 1996:145). Indeed, it is important to recognise that once the data is thematically grouped it becomes removed from an individual 'case' and perceived in a different way, that is, as part of a category. However, Richards (2007:138) cautions that this process has the potential to 'wrench...the data segments out of context'. Further decontextualisation may occur as the researcher illustrates findings with selected quotations because inevitably selected quotations will be those which best reflect the research question, risking further distancing of the participant's original meaning. In other words, when a researcher applies a thematic analysis to a narrative inquiry they must proceed in the knowledge that their analysis and interpretation inevitably detaches the transcript material 'from the social reality from which...[it] was taken' (Glesne, 2006:166).

\section{Ethical considerations}

Miller and Bell (2002:53) recommend that the issue of informed consent 'should be ongoing and re-negotiated between researcher and researched throughout the research process'. This outcome can only be achieved when the researcher is fully committed to protecting the interests of the participants. As Grbich (2004:88) suggests, researchers need to accept their ethical responsibilities for the welfare of participants and ensure to the best of their ability that 'any possible physical or 
psychological harm [participants] may experience... be removed altogether or severely minimised'.

In addition to an ethical obligation to the research itself in terms of independent reporting and interpretation of the results (Cheek, 2008), the researcher needs to balance the potential outcomes for participants and their welfare against the benefits and value of the research itself. Kvale (1996:120), for example, draws attention to ethical concerns which emerge as a result of a researcher's 'over identification' with a project and the associated risk of 'losing critical perspective'. This risk is of potential concern to researchers whose methods involve a relationship of trust with their participant and insider researchers as will be explored shortly.

Finally, a contemporary ethical challenge involves issues associated with technological advances. Public access to data bases and digitalised information has, for example, the potential to impact on the confidentiality of research participants. Researchers need to be mindful of such unintended consequences and where possible to alert potential participants to such possibilities.

\section{Implementation of the research}

I was introduced to Elias by his daughter Lucia who I met by chance at her workplace in 2005. A New Zealand born Lebanese, Lucia agreed to speak to members of her family about my search for potential research participants. Of all the family members Lucia mentioned, the experience of her father seemed most suited to the research aims and objectives. As Lucia pointed out, her father, who had migrated to Wellington from Lebanon in 1953, had 'a lot of stories to tell'. Elias agreed to participate in the research and the interviewing began in July 2009, after a month's delay while he recuperated from an illness for which he was hospitalised.

Some of Lucia's other family members were also interested in participating in the research. As the interviews progressed the decision was made to limit the primary data collection to interviews with just one participant. The reasons for this decision were, firstly the richness and quality of the recorded interviews which offered 'a story contained in itself that hardly requires much extra descriptions and explanations' (Kvale, 1996:145). The second issue was one of time and resources. Once interviewing got underway it became clear that the time frame allocated for the data 
collection (given that the aim was for an in-depth inquiry into the participant's meaning) meant that the collection and analysis of further narratives was not possible.

\section{Ethical protocols and issues}

Ethical approval was obtained from the Victoria University Human Ethics Committee prior to interviewing (see Appendix A). Copies of the information sheet detailing the research protocols and participant rights, and a consent form were given to Elias and his daughters Lucia and Karen, before the research got underway (see Appendix B and Appendix C).

Due to poor health Elias was unable to sign the consent form which was explained to him by his daughter Karen, who signed on his behalf as 'daughter and agent' (see Appendix $\mathrm{C}$ ). This less usual way of obtaining informed consent was a matter for concern in terms of ensuring Elias fully understood the research process. Moreover, his inability to sign the form identified the limitations of relying on formal ethical protocols to protect the interests of participants. As Aldred and Gillies (2002:157158) note, standardised consent forms assume that the information provided is communicated adequately by researchers and is similarly understood by participants. In this case I was reliant on Lucia and Karen to ensure their father was fully informed and this situation meant I could never be sure of the exact nature of the explanations given to Elias when I was not present. Consequently, ethical responsibility for ensuring informed consent and understanding of any possible negative effects such as the loss of family privacy, came down to the quality of the research relationship and the communication between myself as the researcher, Elias as the participant, and Lucia and Karen as intermediaries. To ensure the family were kept fully informed of the progress of the research, I also maintained telephone contact with Lucia, continually checking and trying to anticipate any potential concerns.

A key ethical responsibility was making sure that Elias' health needs were met during the interviewing process. Lucia and Karen, who were present throughout the recording sessions, closely monitored their father's well-being. To prevent Elias from getting too tired frequent breaks were taken and refreshments offered. 
Additional ethical concerns stemmed from the selection of an elderly participant, and Elias' cultural background. Although Elias was elderly and potentially vulnerable, it was important not to assume that he was unable to understand the implications of the research or give informed consent to participate. As Ali and Kelly (2010:123) point out, assumptions of 'vulnerability...can have a disempowering effect on the autonomy of respondents'. Moreover, it was ethically important not to exclude a potential participant such as Elias on the grounds of age or ill health, but rather to be mindful of the particular challenges which make narrative interviewing a 'different' and insightful method of social research (Wenger 2002:273-276).

Undertaking research with a member of a cultural minority obligates the researcher to consider not only the individual but also 'the larger group they represent' (Kvale, 1996:116). This awareness highlights the importance of critical appraisal of ethical issues as they arise and the need to be constantly alert to relationships of power embedded in the research process. For example, taking care not to misrepresent Elias' views or conveying them as representative of other Lebanese people, and presenting the findings in a way that is not detrimental to other members of this community. As Mauthner (2002:2) argues 'qualitative research...is characterized by fluidity and inductive uncertainty' and this makes the outcomes of research difficult to predict. This facet of the research places additional responsibility on the researcher to actively ensure the minimisation of potential harm to participants and their community.

My sense of responsibility to Elias and his family increased as the research progressed. For example, my initial intention was to lodge the interview tapes with the Alexander Turnbull Library. Although additional consent forms were signed for this purpose, after reflecting on the content of the interviews I advised the family to delay this action until we had an opportunity to jointly review the implications of public access. The need for such caution reflects what Grbich (2004:90) identifies as the obligation 'on researchers to maintain appropriate behaviour according to the dictates of their own conscience'. Adding to my sense of responsibility were Lucia's repeated expressions of trust in my ethical commitment to act in the best interests of the family and her desire to have aspects of her father's experience documented for the benefit of the family and the Lebanese community in New Zealand. 


\section{Preparing for interviewing}

The analysis and interpretation of the Turnbull oral history resource prepared me for the interviewing process in a number of ways. Listening to the experiences of other Lebanese immigrants in New Zealand allowed me to identify paths of inquiry and key issues of possible relevance. Equally as important, this process alerted me to the need to carefully approach topics which may be culturally sensitive, cause offence and even interfere with the establishment of the necessary relationship of trust required between an interviewer and the participant (Wenger, 2002:274). For example, I noted in one recording that the interviewer asked a participant to explain what it was like to be Catholic, only to receive the terse response 'You're not Catholic, are you? How could I explain a thing like that to you?'(LaHood, 1989).

\section{The interviewing process}

Before beginning each interview I would take morning tea with the family. During this time the links between my Lebanese grandfather, the Arraj family and other Lebanese families would be discussed. In addition to enjoying this traditional form of hospitality, I recognised that these occasions provided the opportunity to discuss my own Lebanese heritage and connections with this community. These pre-interview sessions became an important part of the research process as they re-established my links with the community as an insider, thereby strengthening the relationship of trust between myself and the Arraj family. Conversely, my insider status raised issues associated with what Kvale (1996:120) refers to as a sense of 'over identification' with a participant. For example, insider researchers may emphasise certain findings which reflect their own attachments in favour of other findings which do not. Consequently the critical orientation of the research design was extremely important as it demanded reflexive exploration of the ways my relationship with the family impacted on the research outcomes (Carspecken, 2008). My research diary proved to be an invaluable tool in this respect.

Drawing on the background literature and utilising some of the questions from the Turnbull oral histories, I formulated an interview schedule of broad themes and openended questions designed to initiate and prompt Elias' reflections (see Appendix D). Three narrative sessions of between eighty and ninety minutes were digitally recorded on separate occasions at Elias' home. A back-up tape recorder was also 
used during the last two sessions. ${ }^{11}$ Brief notes were taken during the interviews, in addition to recording my impressions and reflections, any informal conversations held with Elias, Karen, or Lucia outside the interviewing sessions were recorded in my research diary.

Despite his poor health, Elias was very welcoming to me and appeared much younger than his 82 years. I was impressed by the way he related his memories, reflections, views and impressions. He expressed his thoughts clearly and used drama and humour to communicate import and meaning. Elias also demonstrated his exceptional memory recalling events from his very young childhood. After three interviews were completed data saturation was reached with narrative sequences being repeated and no new topics or themes emerging (Guest, Bunce, and Johnson, 2006).

As a result of the background research I had undertaken, ${ }^{12}$ I was well prepared for the active listening required for effective interviewing. At various times throughout the interviews I used 'introducing', 'follow-up' and 'probing' questions similar to the methods described by Kvale (1996:133-135). All of these techniques were designed to elicit particular responses at given times throughout the dialogue. For example, interpreting questions were used to check my understanding of what was being expressed. Such questions were primarily a means of encouraging Elias to speak and reflect, and to move the interview forward. In this way the discussion was participant-lead.

Finally, the importance of the impact of the interview setting on the nature and quality of the data obtained needs to be acknowledged (Riessman, 2011:315). Conducting the interviews in Elias' family home lent a richness to aspects of the narratives. On one occasion for example, Elias pointed to a chair and described his mother sitting there and the events that had transpired on a particular occasion. We were also surrounded by photographs, mementos and treasured cultural items, all of which were instrumental in Elias' ability to communicate deeply held beliefs of cultural and religious significance.

\footnotetext{
${ }^{11}$ After the first interview session I identified the need for a back-up tape recorder in case the primary recording equipment failed.

${ }^{12}$ Listening to the Turnbull oral history interview recordings.
} 


\section{Roles and relationships}

As Kvale (1996:35) notes, the research interview is 'an interaction' where participants 'act in relation to each other and reciprocally influence each other'. Lucia and Karen's contribution to the research as facilitators, translators and audience was of key importance at every stage of the process. From the outset Lucia as the family spokesperson, acted as an intermediary and gatekeeper facilitating my access to Elias and requesting that both she and Karen be present during each interview to support their father. Lucia's presence was also considered culturally appropriate, as she had introduced me to Elias and I was a stranger to his home.

Lucia and Karen also acted as 'cultural translators' during the interviews, expanding on Elias' testimony by explaining aspects of Lebanese cultural traditions and reflecting on their own experience of Lebanese family life in New Zealand. Their contributions took the form of explanations, interjections and narratives which were also recorded and transcribed. Both daughters also assisted Elias with understanding my questions. Occasionally one or other daughter would correct or challenge a point made by Elias, or prompt him by referring to their childhood recollections and family stories. Such occasions were usually sparked by a query on the chronological sequence of events or a particular detail, and generally ended or changed the course of the narrative, occasionally leading to a topic not being revisited. On one level these interjections resulted from Lucia or Karen's wish to convey accurate details of the family history. However, as Beasley (2006:28) also notes, such interjections can also be interpreted as 'gate-keeping', particularly in a situation when a translator - or in this case a 'cultural translator' - who is not the main participant speaks in 'response to a desire to protect his [or her] family'.

Reflecting on these interruptions and corrections, I also interpreted them as an indication that the process and construction of oral history was taking place. It was evident to me that Elias' memories were passing from individual to family ownership and that this process would eventually lead to these memories being 'owned' by the community and a wider public. Indeed, Lucia confided to me that there were aspects of Elias' narrative that she was hearing for the first time.

Finally, my own role as an 'insider' researcher needs to be acknowledged in the sense that to some extent I had 'membership in the group being studied' (Leckie, 
2008:3). Throughout the course of the research, and despite the fact that only my paternal grandfather was born in Lebanon, Elias, Lucia, and Karen described me as very 'Lebanese' in appearance and character. Both daughters commented that they 'felt at home' in my presence and likewise my diary records my own sense of 'visiting family' during the interviews. Lucia indicated that "Elias did not just invite "anyone" into his home' explaining that my connection to the Lebanese community and the fact that Elias had met my grandfather were the reasons he had agreed to be interviewed by me.

\section{Researcher reflections}

In hindsight, responsibilities for children, medical appointments and travel placed time constraints on the availability of Elias and his family during the interviewing process. These constraints led to three long recording sessions rather than a more desirable series of short interviews. Although well aware of the need to consider Elias' well-being, it was surprisingly difficult to restrict the length the interviews as his co-operation and enthusiasm for sharing his memories often appeared to override his personal comfort. This situation created a tension between my commitment to giving Elias the opportunity to share his story in an unstructured and participant-lead manner, and my recognition that lengthy interview sessions were very demanding for an older person with a chronic health condition. Consequently ensuring Elias' comfort was maintained throughout the interviewing process was not without its challenges. Compounding my concerns was my own sense of urgency to complete the interview schedule while Elias was well enough to share his memories. Similar concerns have been noted by other researchers when interviewing elderly participants (Beasley, 2006:23).

\section{Collecting the Turnbull oral histories}

Consisting of a collection of oral histories lodged with the Alexander Turnbull Library; the 'Walker Street oral history project' was commissioned by the Presbyterian Support Otago Community History Programme in 1988. Sixteen elderly participants including six members of the Dunedin Lebanese community were interviewed with the aim of exploring 'what life was like' in an area of Dunedin which was home to many Lebanese families ( $\mathrm{OH}-\mathrm{Coll}-0951)$. 
Nine oral history abstracts from this collection listed topics which appeared to be relevant to the experience of the Lebanese in New Zealand in the early to midtwentieth century. One abstract, for example, attracted my attention for references made to 'comments on meeting some prejudice against Lebanese at school' and 'remembers the Lebanese community as being very close' (Farr, 1988). Five of the Dunedin interviewees were members of the Maronite Lebanese community and one was a Lebanese Greek Orthodox. The remaining three were non-Lebanese Dunedin residents whose oral histories were explored for their 'outsider' perspective on 'what it meant to be Lebanese'. ${ }^{13}$ As Raleigh Yow (2005:2002) pointed out, research into the experience of a community is enriched when the perspectives of outsiders are included as they provide a sense of the parameters of a cultural group and how an ethnic identity is perceived by others.

While waiting for the retrieval of tapes, which had to be prepared by the librarian for listening, I re-read the abstracts and took notes on the topics that appeared relevant to the research objectives. Examples included: 'Came [to New Zealand] because of father's brother' (LaHood, 1989); 'people in other areas looked down on Lebanese' (Carroll, 1988). When listening to each oral history I took time to pause, reflect and note down points and/or topics which seemed to indicate an important theme employing an inductive approach, that is, the topics selected from the recordings were not necessarily the same as those identified in the abstract. This analytical process required multiple research sessions at the Alexander Turnbull Library.

\section{Analysing the narratives}

A thematic analysis as previously described, was undertaken on the narrative interviews and oral histories from the Turnbull archives. In keeping with the inductive orientation of the research, themes and categories identified from the oral histories were not applied to the interview transcripts, although the same analytical process was employed.

Once the interviewing was completed, the recordings were downloaded, replayed and transcribed verbatim. This was a very slow process but also one which gave me the opportunity to listen carefully to what was said, and to reflect on Elias' tone and pauses so as to achieve a better understanding of what was being conveyed.

\footnotetext{
${ }^{13}$ Further details on these interviewees are included in the following chapter.
} 
Once the main themes were identified they were refined or expanded, new subcategories or lesser themes added, and a map created to visually chart the themes and relationships between them. This technique allowed overlaps to be identified and led to the merging of some lesser themes. Quotations illustrating themes were cross-referenced and added to the relevant theme heading. Identification of word frequency assisted in assessing the importance of themes as some issues were raised several times within and across interview sessions.

Three temporal categories emerged involving Elias' early life in Lebanon; his experience of migration and early re-settlement; and his reflections on raising his own family in Wellington. These three categories were further refined into subcategories. Decisions then needed to be made over which sub-categories should stand on their own, become sub-sets or merge with others. For example, should 'work and employment' be identified as a separate sub-category or become a subset of: 'migration and re-settlement', 'work in Lebanon' ,'work on arriving in New Zealand' or 'working as a family in New Zealand'? Such decisions demonstrate the complexities and 'messy' nature of the data which did not always fit neatly into identified categories and sub-categories. Finally, the narrative structure of the interviews was explored for further insight into the significance and meaning of the identified themes.

The temporal aspects of the narratives were complex and called the main aim and objectives of the research into question. For example, one objective was 'to identify and explore those aspects of a Lebanese cultural heritage which were important to a Lebanese person living in Wellington in the mid-twentieth century'. On reflection, I concluded that a person's a cultural heritage cannot be confined to a particular 'timespecific' parameters. That is, it was difficult to attempt to learn about Elias' experience during a given period of time because it was impossible for him to separate what was culturally important during the 1950s from what he now regards as culturally significant. Reflecting on Frisch's (1990:188) point that as the 'past becomes part of the present...people use it to interpret their lives and the world around them', I discovered Elias' experiences and the value of his cultural heritage was an evolving, living phenomena. 
My sense of connection with the Lebanese community meant I became very engaged with the content of the narratives - a phenomena Riessman (2011:314) refers to as 'narrative seduction'. However, the protracted process of analysis and interpretation assisted me to step back and critically reflect on the relevance of the narratives. That is, I came to recognise the need to look beneath the content of the stories. Gradually I realised that the narratives were not only a vehicle for a particular theme, but that the process of thematic analysis also facilitated access to a deeper level of meaning in terms of the construction and forms of the dialogue. There were times, for example, when I initially assumed Elias was repeating himself or confusing his recollections. As I familiarised myself with the data it became apparent that he had employed several similar narratives to powerfully communicate his experience of isolation as a new migrant in a strange and unfamiliar culture and country. Indeed, Jack (1998:168) advises researchers to consider the potential significance of the 'logic of the narrative'. The way Elias positioned himself in the narratives and portrayed the settings and 'characters' of his past emerged as a key aspect of the research findings.

\section{Concluding reflections}

Withdrawal from the research usually involves the completion of the research process and the severing of the relationship between the researcher and the participants. However, my disengagement was complicated by my insider status involving a growing sense of connection and friendship with Elias and his family who also wished the friendship to continue. The strength of this attachment illustrates yet another facet of the research relationship; one identified by Grbich (2004:89) as involving 'expanding one's close social groups to include participants who otherwise would not be more than passing acquaintances or relative strangers'.

Finally, this chapter has detailed my commitment to the transparency of the research through employing a constructionist epistemology and critical theoretical perspective. In the interests of clarity, the individual components of the research design have been explored in some depth. The decision to include both primary and secondary data in the research design greatly enhanced the scope and depth of the research, adding to the complexity of the analysis and interpretation. 
As a result, I discovered the difficulties of aiming to explore historical experience, and the challenge of minimising the changes in meaning that can occur during the process of decontextualisation, rearrangement and reconstruction of narrative data.

While undertaking this research I achieved new understandings of the role of the researcher and the participants, and the implications of this relationship from an insider perspective. The outcome of this process is explored in the following chapter, which presents the findings and explores the insights obtained from the thematic analysis of the narrative interviews. 


\section{Chapter Three: Findings}

\section{'Different From Any Other'}

This chapter explores aspects of Elias' reflections on his early life in Lebanon and his experience of immigration and re-settlement in New Zealand. The first themes to emerge from his narratives highlight what was culturally important to Elias, and the way this sense of inheritance affected his interpretation of Wellington in the midtwentieth century. The second group of themes concern the nature of the difficulties Elias faced as a new migrant, and his response to these challenges. Also featured in this chapter are themes relating to Elias' religious affiliation with the Roman Catholic Church in New Zealand, and the way this affected his experience of resettlement. The chapter concludes with a group of themes which highlight aspects of individual and collective social change, and reflections on the way these processes are linked with Elias' own experience. Aiming for new insights, Elias' narratives will be presented as they illustrate these themes, together with a discussion of the links with narratives from the Turnbull oral histories and the relevant literature.

Where possible, the narratives are grouped into themes and presented in a temporal order, although occasionally some overlap occurs. My aim is to achieve a balance between presenting the findings in a logical sequence, while remaining true to Elias' narratives. Because of the significance of their contribution, comments made by Elias' daughters Lucia and Karen during the interviews are occasionally included in the discussion and referenced accordingly.

The chapter begins with a brief introduction of the Turnbull oral history interviewees whose narratives are included in this chapter, before introducing the participant Elias and his family. 


\section{Introducing the narrators}

\section{The Dunedin interviewees}

The selected archived oral histories were contributed by members of the Dunedin community between 1988 and 1991. Negia Dale, Albert Farr, Jamelee Joseph, Sam La Hood and Jessie Milne were all born to Lebanese Maronite Catholic migrant parents. ${ }^{14}$ Most of the families originated from the district of Becharre ${ }^{15}$ in the province of Zgharta in Northern Lebanon, and as Maronites were affiliated with the Roman Catholic Church in New Zealand. Jessie Milne visited Lebanon as a child, and Albert Farr was schooled there for four years before returning to New Zealand. The other Dunedin interviewees were Sarah Facoory who was born in Lebanon to Greek Orthodox parents who emigrated to New Zealand: and Redmond Carroll, Elizabeth Briton, and Irene Given who were Dunedin New Zealanders of British extraction. ${ }^{16}$

\section{Elias Arraj and family}

Elias was born to Budwi and Lucia Abi-Arrage on the $28^{\text {th }}$ of January 1928 , in the Maronite village of Sebhel in the province of Zgharta in Northern Lebanon. As the first grandchild in his family, Elias was raised by his grandparents according to Lebanese tradition, and enjoyed a village childhood surrounded by his extended family. As a young man, he worked in Beirut as a general hand at the Regent Hotel before setting off for New Zealand where he intended to visit his uncles and enjoy a working holiday before returning home. With very little knowledge of English, Elias arrived in Wellington in 1953. Elias initially stayed with his uncles and their families in Te Aro, Wellington and gained employment with the Amalgamated Brick and Pipe Co. Ltd. in Miramar. His second job was General Motors NZ Ltd. in Petone, an automobile assembly plant where he eventually worked in a supervisory role.

Elias met his future wife Pauline Romanos, during his first week in New Zealand, although they did not begin dating until several years later. Pauline was born in New Zealand, to a Lebanese family also originating from Sebhel. Prior to his marriage,

\footnotetext{
${ }^{14}$ These interviewees were born between 1906 and 1914.

${ }^{15}$ The capital of the district is the town of Becharre and is also spelled Bsharre or Bcharri.

${ }^{16}$ Facoory, Given, Briton and Carroll were born between 1896 and 1915 . These participants were included for their outsider perspectives (see chapter two).
} 
Elias purchased what was to become the family home in Petone. The couple married in 1958 and raised a family of five children. ${ }^{17}$ At this time, Elias who had anglicised his family name to Arraj became a New Zealand citizen. Elias' sister Zmerid emigrated from Lebanon in 1962 and lived with the family in Petone for several years. Josephine, Elias' second sister, also emigrated from Lebanon arriving in Petone in 1967. Following the death of his father in Lebanon, Elias' mother Lucia joined the family in 1969.

Elias left General Motors after twenty years and began working for Slazengers, a sports goods manufacturing company in Petone. Together with their two youngest children, Elias and his wife Pauline returned to Lebanon only once for a family holiday in 1992, a few years after the end of the civil war. Pauline passed away in 2007. Now aged in his eighties, Elias still lives independently in the family home, with family members living close by.

\section{Cultural inheritance:}

\section{'I am a Maronite’}

The Lebanese people...[have]...a different way of religion [from New Zealanders]... I am a Maronite...Maronites are Eastern Rite Catholics. The priest...can get married... The name of the saint is a very important thing. Most [Maronite] families in Lebanon...know [their]...[family] tree...We know our family tree....I can go back seven hundred years...My family is from Byblos [and they]...migrate[d] to Sebhel. From....Becharre to Kfarsghab, Sebhel - hundreds of villages... [are] all [now] Maronite villages....Lebanese Christian people...in the villages don't believe they are [part of the] Arab [world]. They wouldn't let Muslim go and live up there...The...Syrian Muslim...and the Lebanese Christian [communities]...[are]...separate. [Neither]...treats...[the other] very well.

[In]... Lebanon the Greek Orthodox [live in]...one area...And...Maronite Catholics...live in the other part of...North Lebanon....on the other side of the Ibrahim River...They get on alright, but not when it comes to religion.

Elias drew attention to his Maronite identity very early in the first interview. As the above narratives show, he describes his Maronite identity in religious, historic and geographic terms, and distinguishes the community from the Arab Muslim world.

\footnotetext{
${ }^{17}$ Anthony, Paul, Lucia, Peter and Karen.
} 
His final comment also explains that although both communities are Christian, Greek Orthodox and Maronite Lebanese are distinct groups.

Farr (1988) of Dunedin explained that although the Lebanese Maronites were often conflated with Syrians in New Zealand, 'We're sort of a separate identity - we're from Mount Lebanon'. This difference was reflected in language variants which comprised 'Mountain Arabic dialects'. In Dunedin, Lebanese Catholics 'mixed with other Catholics' and in this way religious beliefs continued to define the Dunedin Lebanese community as it had done in Lebanon.

Elias' reference to family history goes back seven hundred years. By describing his origins in this way, Elias links his own family with what Hareven (1996:242) identified as 'general collective memories of the past'. This strong sense of identity and independence which characterises the Maronite community also emerges in the literature (Cobban, 1985; Zamir, 1985). Elias' narratives (reflecting elements of the literature explored in Chapter One) also suggest that members of the community defined themselves according to religious, historic and geographic parameters (Gilmour, 1983).

\section{'Still in my heart'}

I remember my great grandmother...plain as $A B C$...still in my heart. I was only about three and a half years old....[My great grandmother] was sick and in bed, and my father used to visit [her]...every night after work. [He] used to [take me to visit her] carry[ing] me on his back...every night without fail...rain or shine.

The grandfather comes into it a lot on the name. That's the Lebanese way. I don't know if that's still the way [after] 55 years...here....but when we went back to Lebanon there seemed to me no change.

[My mother]...used to [discipline her own children]...but she wouldn't let anyone touch her grandchildren [in New Zealand] - she'd say, 'they're...[only] innocent little kids'.

These earliest memories of Elias are very significant as they convey the fundamental importance of close family relationships in Lebanese culture. Here Elias reflects on the example set by his father who visited his own grandmother daily, regardless of circumstances. 
Close contact with members of extended family members continued to be a priority for Elias in New Zealand. After they migrated from Lebanon in the 1960s, Elias' mother and sisters lived with the family in Petone for some years before moving into their own homes nearby. Lebanese customs which included visiting family members regularly and attending large family gatherings were also upheld by Elias and his family in New Zealand, as his daughter Lucia (Arraj Stechman, 2009) reflected:

[I remember] as a young child...there was so much...Lebanese family around....Both sides...Mum's and Dad's....Our upbringing had a lot to do with family....There was always something going on...picnics...and gatherings. Forty or fifty people...every other weekend. [Or] we would meet at someone's house...[where] there'd be about half a dozen...blood-related families.

Asked to describe what 'being Lebanese' meant to them, one Dunedin participant expressed the view that 'our people are different; they like to cling to the family' (Milne, 1989). LaHood (1989) said 'it was important to be with relatives'. Indeed, daily contact with extended family was an important feature of a Lebanese childhood in Dunedin and this theme consistently emerged in the oral histories with interviewees describing regular outings with large groups of extended family members who would 'gather' for picnics in summer (LaHood, 1989).

The custom of grandparents raising the oldest grandchild and of the grandparent's name being bestowed as a child's second name to signify this relationship also emerges from Elias' narrative. Significantly, he found that when he returned to his village in 1992, this tradition had continued. The importance of the relationship between the Lebanese grandparent and child continued in New Zealand as indicated by Elias' description of his mother's special relationship with his own children.

All of the interviewees emphasised the fundamental importance of having grandparents. LaHood (1989), for example, recalled feeling 'envious' of Lebanese children who had their grandparents 'with them' in Dunedin.

Facoory (1989) described accompanying her grandfather everywhere because he 'had no English' and Milne (1989) recalled 'how lovely' it was to 'meet grandparents in Lebanon because we didn't have them [in Dunedin]'. 


\section{'The Cedar of Lebanon...is...the most important'}

[l'll] tell you the truth. I know you're Lebanese and probably somebody already tell you.....Nothing is lovelier and nicer than The Cedar of Lebanon...that's the most [important symbol of] our heritage.... The tree itself is different from...any other....It's special. You've got a lot of cedar in the world but it's nothing like it....[The Cedar is]...dark, dark green in Lebanon. They name...the trees....[One is known as] Our Lady's Tree.... [according to] legend...Our Lady...visit[ed] the Cedar of Lebanon and she slept under that tree....I've been up that hill...[to] the Cedar [Grove]...many time[s] when I was in Lebanon....and every time...my hair always goes up [at the back of my neck]....A Priest [who visited the Cedar] said to me, 'The Cedar of Lebanon is the most beautiful thing I ever seen in my whole life'. I [asked him]...what [he] meant - the Cedar or the land? He [replied] 'Everything'. Other people....who [have experienced visiting] the Cedar ...said [to me] ... 'We [felt] like we [were] in Heaven. We [now] know when we die where we go'.

The Cedar...[are] looked [after] by the government and...the French, American[s] ...German[s] and...Italian[s]....They don't want the cedar to die....One of the oldest cedars...[is]...seven thousand years old....You're not allowed to...touch [them]...especially after the war in Lebanon [which]...nearly got them....The [fragrance] ... of cedar wood...never goes.

There's a lot of Lebanese people [in the world] but they [are] all mostly outside...like Lucia...like you...born...here. Your grandfather was Lebanese...

The image of a green cedar tree appears as an emblem on the Lebanese flag; but its cultural significance for Elias as the above narrative conveys, relates to the living trees known as the Cedars of Lebanon found in Becharre's district on the mountain slopes. $^{18}$

Elias alludes to the sacred nature of the Cedars of Lebanon by relating a religious legend and likening the experience of being near the trees to being 'in Heaven'.

It is significant that Elias draws attention to the way a priest does not distinguish between the trees and the land, and in this way emphasises that the Cedars originate from Lebanon. Just as he defines the Maronite community, Elias describes the Lebanese Cedars in religious, historic and geographic terms - they too have 'lived' on Mount Lebanon for thousands of years, are vulnerable in wartime and are 'looked after' by European interests. Although there are specimen cedar trees throughout the world, as Elias explains the Lebanese Cedars themselves are inextricable from both the land and the Maronite people themselves.

\footnotetext{
${ }^{18}$ The grove is also known as The Cedars of God (Mirepoix, 1969).
} 
Finally, Elias' reference to the fragrance of the Lebanese Cedar at the end of the narrative refers to an event which occurred during one of the interviews. While discussing the importance of the trees, he asked for a bowl to be brought down from a shelf in the living room requesting me to inhale its scent. The bowl had been brought back from Lebanon after the family holiday. In making this request while speaking of the Cedars, I understood that the narrative interview situation had allowed Elias the freedom to convey a sense of his fundamental beliefs about his own Maronite cultural identity and the way it is transmitted down through the generations. Despite emigration and re-settlement, Elias' cultural heritage, like the fragrance of the cedar bowl, 'never goes'. Despite the fact that his own children and the children of other migrants may now live 'outside the country' they still, according to the meaning he expressed in these narratives, remain inextricably linked with their origins.

A great strength of the narrative history interview in this case was that it allowed for 'the interviewer's empathic access to the meanings communicated' (Kvale, 1996:129). While reflecting at some length on the complex meaning of these narratives, I found it useful to consider as Mishler (1999:8) suggests, that:

Participants select and assemble experiences and events so they contribute collectively to the intended point of the story...why it is being told, in just this way, in just this setting.

Lebanon was always 'home' to the migrant parents of the Dunedin interviewees. La Hood (1989), for example, pointed out his belief that 'all immigrants including the Lebanese' regarded their 'birth country' as 'home'. For this reason, the New Zealandborn interviewees considered New Zealand 'home' although they were also 'conscious' of being Lebanese (Facoory,1989). The complex nature of the issue of ethnic identity of these migrants was poignantly observed by one interviewee. Elderly migrants always wanted to return to Lebanon which they considered their home. If they did manage to return, however, invariably they would want to go back to New Zealand because so much had changed in Lebanon - it was no longer the home they remembered (La Hood, 1989). 


\section{'Because my uncles [were] here...'}

I came [to New Zealand] because my uncles [were]...here....I thought l'd only be here about three or four years....When you're young, you just want to go somewhere.... The Regent hotel [in Beirut where] I used to work...sent me a couple of letters [saying] my job [was] still there...they [were] hold [ing it open for] me. [Eventually] I had to write to them...telling them I [wouldn't] be back.

I believe some [migrants]...used to come...to the wharf in Beirut and pay the boat [and go]...wherever [the boat would take them]....A lot of...[migrants]...didn't know where they were going. Some of them ended [up] in Australia and some of them ended [up] in America...[or] Brazil.

Elias explains that he was motivated to leave Lebanon for two main reasons. The first was to fulfil his family obligations as the oldest grandchild by visiting his uncles and the second to have an overseas working experience. During the first recording session, Elias' daughter Karen (Arraj-Fisher, 2009) also described her father's motivation to leave Lebanon: 'Dad being the oldest grandchild he came out really to visit his uncles. Just to work for a few years and then go back home'.

In fact, Elias did not originally intend to emigrate permanently from Lebanon and by explaining that his job was left vacant for him, indicates that he did not leave the country with the purpose of finding long-term employment. Even when he eventually wrote back to his employers in Lebanon advising them that he would not be returning to work, Elias did not intend to stay in New Zealand permanently. Off-tape, he told me that over time he came to 'like the country' (meaning New Zealand) and decided to continue working here for a few more years in order to buy 'a very nice house back in Lebanon' with his savings. He only decided to settle permanently when he began dating Pauline four years after his arrival in New Zealand.

The Dunedin interviewees offered various reasons for their parents' decision to migrate from Lebanon to New Zealand, including religious persecution and the prospect of better economic opportunities outside Lebanon (Farr, 1988; LaHood, 1989). These explanations are more consistent with the 'push and pull' factors offered by Akoorie (2007:763). Negative factors such as poverty were the 'push factors' which motivated the Lebanese to leave their homeland, while the prospect of employment attracted migrants to New Zealand and was therefore a 'pull factor'. Dale (1989) for example, understood her father had been recruited by an uncle who 
'put him in business' in New Zealand because he 'only had one daughter and needed a son'. This case also provides a good illustration of the way that as Akoorie (2007:774) suggested, Lebanese migrants were able to mobilise family networks by encouraging family members to migrate from Lebanon to help with their businesses in New Zealand.

\section{Culture shock and other challenges:}

\section{'The hardest thing for any foreign person...everything was closed'}

When I arrived [at the]...wharf...and I got off [the ship]...I asked...'Where are we?' And I cried. I really cried....Because...I had left Beirut, the most beautiful city in the world, to come to Wellington.... The biggest building was a [small-sized] office block in Kent Terrace....Beirut used to be open twenty four hours.... missed everything...in Lebanon...[especially at the] weekend - the pictures, the hotel[s], all the entertainment. They used to have...six or seven...licensed...gambling clubs [Casinos] in Beirut. You [didn't]...have to have a license in the towns [or villages].... There was one race course called 'Across Beirut'. Thousands of people used to [attend] every Sunday. They used to sit...up the hill...in cafes and restaurants...and wait for the race....

You come [to New Zealand]...and...everything [was] closed. There was only the picture theatre - eight o'clock I think the last film [was] - finished by half ten....You can't even have a cup of coffee. If you smoke and you want a packet of cigarette[s] you can't buy a packet... That mean[t] you [had]... to [buy] ...bread [on] Friday for Saturday and Sunday.

The...corner dairy...used to open [for] a couple of hour[s] in the morning...and then close 'til five o'clock.... They [weren't]...allowed to [stay] ...open....If you want a bottle of milk...you got no show in the world of getting any....and it's a milk [producing] country too! If you want a pound of butter - you go on Saturday [to]...the dairy. They [had]...to sell it to you in secret and put it...in a bag for you. [They'd tell you] 'Don't say anything!' And they [wouldn't] sell it to you unless they [knew]...you....I thought [this aspect of everyday life in New Zealand]...was horrible!...I didn't [understand] the[se New Zealand] customs.

When you went to the restaurant [in]...those days you could only ask for three different things...steak, pork chop[s], or lamb chop[s]. That's all, nothing else.... One day...I said to the [waiter]...'Will you give me some potato? Something [different].' He looked at me and he didn't understand me.... He brought me a piece of steak with one potato and...[a few] peas.

Elias' expectations of Wellington reflect his experience of life in Beirut which was a much larger, European-influenced city. Despite Hitti's claims (1957:476) regarding the 'adaptability' of Lebanese migrants, Elias' narratives do not suggest that he 
initially felt 'at home' in Wellington. Indeed, Elias' first impressions of Wellington convey a traumatic experience of culture shock.

The literature contains examples of similar reactions from European migrants in the 1950s. One woman for example 'wept' when she first saw Wellington 'because of its ugliness', while another described expecting more from '[New Zealand's]...capital city [which] seemed like a small provincial town in Europe in...every respect' (Beaglehole, 1988:31-33). Dutch women also expressed their dismay at the diminutive size and appearance of New Zealand's capital city (Doornbos, 2006:39).

These accounts reflect aspects of the literature which explore the experience of migrants who, as Trlin (1979:8) suggested, brought the values they developed in their homeland with them. This disparity between the expectations of migrants and the reality they faced often determined the extent of culture shock which they experienced (Berger, 1963:23). Elias' inability to comprehend weekend closing hours; the associated lack of entertainment, and restrictive attitudes to socialising was also reflected in the literature (Beaglehole, 1990:13,21; Doornbos, 2006:39).

English migrants in Wellington spoke of their 'early months' in the city as 'ones of consolidation and coping. And trying to find something to do in weekends' (Hutching, 1999:145).

European migrants also expressed surprise at the extent to which they felt 'down' about the 'small things' including a lack of variety in the New Zealand diet (Beaglehole, 1988:33; de Bres, 1997:2). One new arrival in Hamilton for example, reflected 'there was [only] one kind of bread...you had to like it or lump it' (Beaglehole, 1988: 41).

\section{'You walk down the street - you don't see a person...'}

In Lebanon [our family name was]...Abi Arraj. But...[when] my uncle[s came]...to New Zealand they...shortened...it...to Arraj.... [came]...to New Zealand and I wanted...to reduce my name.... The...police [asked] me...'Why [are]...you called AbiArrage [on your passport?]'.

One day it happened [that]...it was three o'clock in the morning. I wanted to go back to Wellington [after attending an]...engagement party. I wasn't expecting [there would be] nobody....at Wellington railway station. I [was] walking [up]...Lambton 
Quay...right...through...up the top of Willis St to go to Thomson St...all by myself....I [only] knew a few words [of English]. A policeman [appeared] who walked with me. [He] said, 'Are[n't] you scared?' And I said, 'how can I be scared when there [are] no people?' And he said, 'Where [do] you come from?' And I said, 'I come from Lebanon.' Oh, he said, 'It's not like Lebanon....You're not in Lebanon [now] you're in Wellington...[there's] nobody in Wellington'.

Come...the weekend, Saturday from 6 o'clock on to Monday 9 o'clock you... walk down the street you don't see a person....[Walking through]...Lambton Quay one day...there was nobody...A policeman... asked me what I am doing and I said 'I'm going to church what do you think I'm doing?' [Then] I said [to him] 'Where [did all] the people go?' And he laughed and said, 'the people [will]...still be sleeping. It's ten o'clock in the morning'. He [asked] 'Where are you from?' And I said 'I'm from Lebanon.' And he didn't even know where Lebanon...[was] and I couldn't speak [enough] English to tell him where [it was]....He sa[id], 'Okay' and he walk[ed] with me. He...[asked] 'what language you [do you] speak?' I said 'I speak Lebanese'. I didn't tell him Arabic...Lebanon doesn't like to be an Arab.

Lebanese....believe in dress[ing well]...especially when go[ing] to visit [family] or...in the [cities]. [It] doesn't matter how poor or how rich [you are]...

Off-tape, Elias explained that he is known as 'Les' in New Zealand. Dutch migrants also described the anglicising of their names - sometimes done without their consent - because the English versions were easier for New Zealanders to pronounce (de Bres, 1997:3). This also appeared to be the case with members of the Dunedin community; Milne (1989) for example, reflected that the anglicised version of her name was 'not a very good translation' of her Lebanese name.

The first very brief exchange recalled after more than fifty years draws attention to Elias' experience of being questioned by the New Zealand authorities. Indeed throughout the narratives, Elias repeatedly draws his audience's attention to the presence of New Zealand policemen. This is significant because it communicates his feeling of unease, together with a sense he is being watched or followed. Despite being disadvantaged by his lack of English, Elias answers back when he is challenged and continues on his way.

Elias' descriptions of empty Wellington streets convey his sense of his loneliness. Similar observations about Wellington were made by English migrants in the midtwentieth century; one new arrival reflected on the 'scene of windy desolation that was Lambton Quay', and another said of Sundays 'it seemed the whole country was asleep' (Hutching, 1999:145-146). 
Elias' sense of cultural identity also emerges from the above narratives. The importance of church-going on a Sunday morning suggests he considers this should be obvious to the policeman, while his comment that he speaks 'Lebanese' rather than 'Arabic' makes it clear that he is not of Arabic origins.

In the final section of the above narrative Elias' reflects on his perception of the differences in the dress code between Lebanon and New Zealand. During the second interview, Lucia (Arraj Stechman, 2009) recalled her father explaining that as a Lebanese migrant he had felt visibly distinct from the wider New Zealand community:

Dad always talked a lot about when he came over to New Zealand...he['d] walk...around the streets with members of his family looking quite different... even his suits and...hairstyle...was completely different.

Elias was aware of being visibly different from other New Zealanders and this aspect of immigrant experience is raised in the literature. Veitch and Tinawi (2006:211) for example, suggested that because of their dress sense and emphasis on grooming, Lebanese migrants in Dunedin looked different from other New Zealanders. While it is clear that Elias is aware of his different appearance, his narratives suggest that the reactions of others were neutral. In this respect, Elias' reflections contrast with the literature which suggests that New Zealanders were negative with regards to the visual and cultural differences of migrants during the 1950s (Akoorie, 2007:777; Beaglehole, 1990:13).

Reflecting on his experiences of growing up in a Lebanese community Farr (1988) recalled that the Lebanese in Dunedin were 'treated like most other ethnic groups not as equals'. LaHood (1989) indicated that the Lebanese were considered 'foreign' by members of the wider community who would 'show...they didn't want you'. These recollections were confirmed by 'outside' members of the Dunedin community who observed that the Lebanese 'didn't get a fair spin at school' and were 'looked down on' by other ethnic groups (Briton, 1988; Carroll, 1988). One woman (Given, 1988) even remarked that she 'couldn't stand the Lebanese' and considered them 'unscrupulous'. Lebanese children also experienced ethnic prejudice at school, sometimes at the hands of the Irish nuns or the Christian 
Brothers, although this treatment was put into perspective by Farr (1988) who pointed out that 'no-one was well-treated well by the Brothers who were severe'.

However, Milne (1989) recalled being caught and disciplined by Irish nuns for saying 'God Bless [Lebanon]' during prayers at school when they were supposed to say 'God Bless Ireland'. This aspect of migrants' education in New Zealand was not uncommon. De Bres (1997:3) for example, recalled that he was also expected to 'adopt' the British origins of the dominant migrant group.

\section{'I had to learn everything...'}

I went to the English movies quite a lot. In Lebanon, and New Zealand. I used to love the...American...cowboy movies.... [only] used to know a few words [of English]...mostly swear...words....I [had] ...to learn everything....About...four years later...my English improve[d]...when I start[ed] to go [out]...with Pauline....

[At first Pauline didn't want to talk with me]...because I couldn't understand what she was saying....She said, 'I'm not telling you anything unless you ask me in English'. She [taught me]...a lot.

My father wouldn't come [to New Zealand]...wouldn't leave the country. I'd try [to get him to come too]...[l'd]...send him a letter...there never used to be [any] telephone[s]. He said 'no'. He wouldn't come [to New Zealand].... He said 'you come back'...

The old Lebanese people...[would] want me to stay with [them but]...I didn't want to stay [with them]....My [future] wife's grandfather...[came] from the old country...when he was.... a few years old....When I [came] to New Zealand he['d] been here about eighty years....[He] said the [restrictions on entertainment and shop opening hours]...was a great thing....And I [don't know]...why [he said that].

The most significant of the practical challenges Elias faced when he arrived in New Zealand, was that he had very little knowledge of the English language - most of which he learned by watching American cowboy movies in Beirut. As the above narrative shows, this situation continued until he began dating his future wife. Most of the Dunedin interviewees reflected that the disadvantages their parents experienced due to a lack of English were never resolved. All of the Lebanese interviewees said their parents had limited opportunities for employment as a result, and even when they had learned enough English to 'get by' they did not readily engage with members of the wider Dunedin community (LaHood, 1989; Facoory, 1989; Farr, 1988; Dale, 1989). 
Lebanese migrant parents tended to accept such problems without complaint, the interviewees reported, although employment-related issues were raised. Dale (1989) for example, recalled that her father had all his small-goods stolen while hawking and did not have sufficient English to be able to tell the police.

Elias was eventually able to learn English, because of Pauline's friendship and support. This was made possible only because Pauline's father, who had arrived in New Zealand as a young child, had welcomed Elias into his home. However, the potential for misunderstanding because of language difficulties meant that such avenues of support were fragile.

Off-tape, Elias also described some of the difficulties he experienced when trying to communicate with older Lebanese people who had arrived in New Zealand as young children. He explained that 'the older people had...lost some of their...Lebanese language' while he had difficulties understanding 'their English'.

There were also differences of opinion between Elias and other members of the older generation of Lebanese who had lived in New Zealand for many years. As the above narrative shows, different attitudes to aspects of life in New Zealand often reflected a gradual acceptance and adjustment to a New Zealand way of life over time. As Scuro pointed out, 'The problem for readjustment for the adult immigrant is quite different from the problem of the child immigrant' (Odencratz, cited in Scuro, 2004:9). These differences also had the potential to cause misunderstanding and disagreement within the already very small Lebanese migrant community.

Elias missed his close relationship with his father back in Lebanon and despite repeatedly trying to encourage his father to join him in New Zealand, never saw him again. His only channel of communication with his father was by letter which was often not satisfactory, and Elias sought guidance from his uncles, as his closest male family in Wellington. However, Elias' uncles could not replace the primary family relationships that Elias missed. Differences in opinion arose for example, over the important question of Elias' marriage to Pauline. Despite the approval of Elias' parents back in Lebanon, Elias' uncles in New Zealand disapproved of his engagement to Pauline. 
Elias' daughter Karen (Arraj-Fisher, 2009) explained:

Dad's uncles didn't come to [his] wedding...Dad's...uncles...weren't happy....They thought Dad should marry someone else they'd already thought about...in Lebanon. But Dad started going out with Mum and that was it.

Milne (1989) said 'all [Dunedin Lebanese migrants] felt homesick'. Lahood (1989) said his mother 'found things ...totally different [in New Zealand] and missed her sisters'. Dale (1989) said her mother 'was homesick for her [own] mother [in Lebanon]' and struggled with depression and regrets. Other migrants found the separation from parents and loved ones in Lebanon very hard to take. George Bouzaid for example, suffered due to his separation from family members in Lebanon (Bouzaid, 1992).

\section{Strategies and support:}

\section{'You do your work and you're alright'.}

[My uncles]...helped me [find] work in the Pipe and Brick Factory...in...Miramar. There...[were] quite a few different nationalities...but mostly Kiwis [working there]. I was the only Lebanese. The manager used to call me Eli... he was very good to me. On Fridays we used to have a couple of drinks [after work at]...the Railway Hotel in Newtown [but the manager] died in my arms...[after an accident at work]...and I could never work...there again after that. I got a different job in General Motors...Petone, the next day....I was with General Motors for twenty years [as a]...charge hand with eighteen people...[reporting] to me. I met quite a few friends...[and] only left...because the Union got on my nerves. Every week [it seemed we had to] stop work. 'I can't afford it, mate,' I said [to the Union]...'I've got a family'. After that I work[ed] for Slazengers....and that was really my best job...I got on with the manager very well. I [did] my work. You do your work...and you['re] alright...[I was used to] heavy work at General Motors....[At] Slazengers [I] could do three or four times more...l'd finish the work [they gave me and the manager]...used to tell me to [take some time out]...to go for a walk...

As the above narrative shows, Elias was valued by his employers and through his work made contacts and formed friendships with members of the wider community. Elias' work ethic was described by Lucia (Arraj Stechman, 2009):

Dad...very rarely took his sick days off - he would have to be...crawling on his knees, ill. He would work overtime...evenings [and] Saturdays. [He] was absolutely conscientious [and] never late. 
Elias' last job before retirement was at Slazengers in Petone where he was so efficient his manager would tell him go down to the beach and have a swim during working hours. Every member of Elias' immediate family including Pauline and their five children, worked at Slazengers at various times in different roles; Elias' sisters Zmerid and Josephine were also employed by Slazengers. Karen (Arraj-Fisher, 2009) explained why Elias described this job as his 'best' experience of his work in New Zealand, 'It was a good job. We were all there together, all the family. He loved seeing his sisters every day'.

All of the Dunedin interviewees described parents or grandparents who at one time, travelled to rural areas selling small goods - an occupation which was known as 'hawking' (Veitch \& Tinawi, 2006:209). Carroll (1988) reflected that the Dunedin Lebanese had difficulties finding jobs while Dale (1989) recalled that English workers on the wharf were 'favoured' over the Lebanese. Farr (1988) also noted that conscientious work habits helped the Dunedin Lebanese form new social networks:

'Once New Zealanders knew the Lebanese at work, they were well-liked and accepted, and [the New Zealanders] would have a drink with them'. Members of other migrant groups also recalled how New Zealand working conditions were different from what they were used to in their home countries. Hutching (1999:1367) for example, found that many British migrants reported 'being told to slow down because they were working too hard'.

Unlike many Lebanese in New Zealand, Elias was not self-employed, nor did he run a family business. Consequently his experience of work was typical of that reported in literature on other Lebanese migrants (Akoorie, 2007; Hitti, 1957:475; McGill, 1982:108; Moodabe, 2000; Scott, 2002). Elias' value to his employers however, facilitated employment for every member of his family. In this way, he achieved the integration of work and family life that Gilmour (1983:14) observed, was a traditional part of life in Lebanon.

\section{'We used to go to the Lebanese Club'}

A lot of Lebanese people [lived]...in Mt Victoria. I was only here about three weeks [when] I met Masoud...walking up Elisabeth Street...and [he said]...something...[to me] in English. I [heard him]...singing....and I said to him, 'You['re] singing...a...Lebanese song'. I got to meet him....He [invited me]...to visit...him. 
My wife's grandfather...[wanted to]...give me [a]...room for free. Because there was nobody in it anyhow...I wouldn't stay [though]. I stayed with my [future] father-inlaw...he charged me [a reduced rate because we came]...from the same village. I didn't stay long.

I didn't really want to...visit...all the Lebanese homes in Wellington...I had my uncles....My aunty used to cook Lebanese food. I picked...three or four different Lebanese [homes]...I used to go and visit.

We used to go to the Lebanese Club...in Cambridge Terrace....and [later]...Abel Smith Street....If you [were] Lebanese you [could] come along. They [also] used to let some Greek [migrants]...in to socialise with us....They...played snooker, billiards...mostly cards....It was open weekends and weekdays...In the end they got too greedy and start[ed] to play poker and somebody told on them. That's [when] the...police...came and closed them....The first time [the club was closed]...just for a couple of weeks. But they rent[ed premises]...and...start[ed] to play poker...again. And they got caught and the [police] closed the club [for a second time]. The club never really...[started up]...again.

In Courtenay Place [Wellington]...I used to [go to]...a Greek cafeteria [where] they had lovely food...similar food [to the Lebanese]. The old lady...used to open the [pot] lid to show [me] what [she...was cooking]. She [couldn't] speak [much] English...and I [couldn't]...speak Greek...[but] she [always] used to say, 'Talk Greek to me. Call me Mama'.

[A Greek man owned]...one of the best restaurants in Wellington in those days...He was a good friend to me...when I just [arrived]...in the country. He used to give me cut prices in everything. He said, 'If you['re] Orthodox you can marry my daughter'. I said 'No'....... [knew] a lot of Orthodox back home - they used to say the same thing...When he [saw] Pauline with me he said, 'A Greek girl?' And I said, 'No. She's Lebanese'....And he said 'She's not Greek Orthodox?' And I said, 'No. She's Catholic'. And he said, '[That's]...no good.' I used to take the family to [his restaurant]...every Christmas...'

Elias described the concentration of Lebanese families living in Mount Victoria in the 1950s, and his sense of delight at meeting another Lebanese completely by chance in Wellington. Living near other Lebanese migrants helped to allay Elias' feelings of isolation and homesickness, and helped him to form friendships with other Lebanese outside of family networks. Karen (Arraj-Fisher, 2009) commented that living in Mount Victoria helped the Lebanese to feel more at home, 'They...[the Lebanese]...all liked living in Mount Victoria...[where] all the houses [were] on big hills. It reminded them of [home because]...Lebanon is very mountainous'. 
The Lebanese Club was an important meeting place because it was open for entertainment and socialising when alternative venues in Wellington were often closed after work and during weekends. As discussed earlier Elias draws attention to the fact that gambling was culturally and legally acceptable in Lebanon in contrast with the situation in New Zealand. Although he attributes the forced closure of the club to the illegal gambling which took place there, his narratives also suggests that the New Zealand police were monitoring the club's activities. This suggestion is consistent with Trlin's (1979:163) observation that immigrant associations or clubs were 'typically viewed with suspicion' and subject to 'close surveillance if not declared illegal and closed down'.

In the case of English migrants, Hutching (1999:140-141) describes the establishment of 'New Settler Associations' in 1948 which aimed to 'promote social contacts and closer ties of friendship' between 'New Settlers' and 'New Zealanders':

Branches [were established]...throughout the country and a club magazine ....in Wellington....It was a lifeline for those who were finding the shock of living in New Zealand almost too much to cope with.

These associations encountered negative feedback from members of the wider New Zealand community. Hutching (1999:143) cites a letter from a Nelson resident who wrote to their local New Settler's Association:

...you might like to know what the average 'Kiwi' thinks about your Association. In the first place why should some of our own New Zealanders have to take second place to immigrants (and not only from England, either)...if people want to come to this country can't they stand on their own two feet, without being propped up by a crowd of others?

Elias' narratives also show how he was on friendly terms with members of the Greek migrant community and recalled socialising with them at the Lebanese Club.

Seeking a more varied cuisine than what was offered in Wellington at the time also drew Elias to Greek food establishments. Indeed, the literature implies that the search for more variety in diet was common ground for migrants of different origins; de Bres (1997:2) described a Wellington delicatessen which attracted customers from six different cultural origins.

Elias also recalls being offered discounts by Greek migrants in the same way he describes the financial support extended to him by Lebanese migrants from his own 
village. 'Price discounts' were one example of the way that 'social capital' (Akoorie, 2007:775) was mobilised to assist Lebanese migrants economically.

The anecdotal evidence provided by Elias suggests that this form of 'economic action' also existed between the Greek and Lebanese migrant communities, and that these support networks both reflected and initiated the social connections between them.

Another significant theme which emerges from this narrative concerns Elias' recollection of the conversation with his Greek friend on the topic of Pauline's religious affiliation. Looking closely at the order of the narrative, it is evident that Elias' friend checks that Pauline is not of Greek Orthodox religious affiliation after being told that she is Lebanese. This sequence of events implies that national origin is not being used in itself as an indicator of affiliation to a particular migrant community in Wellington. As the literature suggests, this was also the case in Lebanon where a Greek Orthodox or Lebanese Maronite identified themselves according to their church affiliation. In this way a Lebanese migrant's sense of cultural identity in Wellington continued to reflect their religious beliefs.

In describing their everyday lives and family activities, all of the Dunedin Lebanese interviewees recalled their migrant parents taking part in a very social community who met regularly to talk about Lebanon, play games and listen to music. Social support networks were confined to this community whose members 'looked after their own' (Milne, 1989). As Akoorie (2007:776) pointed out, the Lebanese Dunedin community was somewhat unique in New Zealand, because of the large number of Lebanese families who had settled there. Established in 1956, The Cedars of Lebanon Club in Dunedin still flourishes. As Akoorie (2007:774) observed, the historical social networks of these migrants 'were replicated locally through multiple working, religious and recreational ties, all linked to one another by residential proximity'. 


\title{
Elias and the Roman Catholic Church in New Zealand:
}

\author{
'I never thought it was a church...it was a dance hall'.
}

St George's Church in Beirut is...beautiful...[and] very big. Everything...has a meaning and the land...[is sacred]. If they want to build a new [church]...they [have to build it] ...next to [the old one]. They [won't]...pull the old one down...because the people... [would] cry like anything...Still...the old people...want to go the old church.

I used to [attend]...St Joseph's Church... because I lived in Austin St....St Joseph's church used to be full of Lebanese in the weekend. I met your grandfather there [Elias refers to my own grandfather, Joseph]...The Peters, the Soods, the Montagues...the Romanos ....and the Arraj families.... They [all knew]...each other....I never thought it [St Joseph's Church in Wellington]...was a church....It was a dance hall! There were three or four Lebanese [formed a committee]...trying to build a new church. They collect[ed a lot]... of money...[from] the Lebanese people.... Then the Bishop took the money from St Joseph's...to build another church somewhere else. And the... [Lebanese people] gave up...on their [plans for the] new church - they gave up.

Ordinary [New Zealanders]...don't know what [a] Maronite Catholic is...[but]...you go to a Catholic Church [and] the priests they know [about ]...Maronite Catholic[ism]. The priest[s]... [were]...absolutely...good to me. They [understood]...I wasn't very good at speaking English. They tried their best to get me ...[to go]...Catholic dance[s] in St John's Hall [which]...used to be in Vivian St. I went once. [There]...used to be about 90 percent Polish girls...One of the priests...introduced me to one [of the Polish girls]...to [help me]...mix ....with the wider Catholic community... I said to [the Priest] 'I can't speak English'...I didn't really...need [to mix] ....because I had my uncles...I had a few friends and I [didn't]...speak [enough] English to introduce...[myself]to a girl.

[After moving to Petone]...we met [our very good friends]...Betty and John...in Sacred Heart Catholic Church....in Petone. They were from Manchester, Salford. I couldn't understand what [Betty]...was saying. Pauline...[was]...born in New Zealand and she couldn't understand what they were saying [either]....And in the end...[Pauline]...said: 'I'm going to teach them how to speak...[in] the New Zealand way!' [Then we]...start[ed] to understand them.

Elias' expectations regarding the proper appearance of a church building reflected his religious beliefs and the cultural values of his upbringing in Lebanon. The clash of these pre-conceptions with the reality of the situation in Wellington, is a further example of the disparity which had the potential to cause culture shock for migrants with different viewpoints. As well as a place of worship, Elias' recalls St Joseph's was a focal point and meeting place for members of the Lebanese community who 
congregated there. Reflecting on the efforts of Lebanese parishioners who fundraised to build a new church, ${ }^{19}$ Elias' narrative conveys the community's powerlessness and sense of injustice at the outcome, and the bishop's insensitivity to the cultural significance of a beautiful church to the Lebanese community.

Elias' sense of gratitude for the support given to him by the Catholic priests of St Joseph's is evident in his narrative. Part of this gratitude reflected his socialisation as a Maronite Catholic as this link contributed to Elias feeling 'understood' by the priests. They were also sympathetic to some of the challenges faced by Elias as a new migrant, particularly with regards to his struggles with English. The priests encouraged him to attend dances which allowed him opportunities to socialise with members of the wider Catholic immigrant community. In exploring the links between the Catholic Church and the Irish migrant community in New Zealand O'Shea Miles (2004:84) found a similar situation, noting that 'young people were exhorted to mix, presumably to increase the chance of endogamy (marriage within community)'.

However as Elias' narratives also indicate, his primary supporters were members of his own extended family living in New Zealand and friends from the wider Lebanese migrant community. It is also important to note that initially, Elias views his lack of proficiency with English at the time as an obstacle when it came to socialising with members of other ethnic communities.

Later, when Elias' moved to Petone with Pauline, his membership of the Sacred Heart Catholic Parish eventually helped him to form close friendships with migrants from other places of origin. Hutching (1999:150) also found that English migrants formed friendships through their affiliation with a church.

The reflections of the Dunedin interviewees provide additional insight on the importance of religious ceremonies such as wedding ceremonies and funerals, to Lebanese migrants. One interviewee for example, explained how once baptised, a child 'belonged to the [Catholic] Church and the [Lebanese] community' (Milne, 1989). This observation highlights the significance of the link between the Dunedin Lebanese community's cultural identity and its religious affiliation. Christenings, First

\footnotetext{
${ }^{19}$ Elias told me that my own grandfather (Joseph) had been on a committee fundraising for a new church. I wasn't aware of this prior to the interviews.
} 
Holy Communions, Confirmations, weddings and funerals were considered very important religious occasions and were a source of vivid memories among all of the interviewees.

\section{Points of social change:}

\section{'Jiddi was a very clean man'.}

I don't think [cleanliness]...is a cultural thing....Pauline]...loved her [cleaning] job...because she loved everything to be nice and clean...[She] was like her father. Jiddi (Grandfather) was a very clean man.

I think it's different [for Lebanese Maronites who]...believe in dress[ing well]. Rich or poor...they're all...clean....[Some other religious communities]...in Lebanon [are] not very clean.

Despite referring to Pauline's habit of cleanliness and tidiness as a trait she inherited from her Lebanese father, Elias did not identify these habits as being particularly 'Lebanese' in character. Pauline and Elias were however, described by their daughters (Arraj-Fisher, 2009; Arraj Stechman, 2009) as exceptionally 'clean and tidy people'. The links between Lebanese people and cleanliness is a theme which emerged in different forms throughout Elias' narratives as indicated by the examples above. This is an example of the way narratives have the potential to express the contradictory views of a narrator, and these inconsistencies can highlight the significance of a theme. Jack (1998:168) for example, drew attention to the need to consider the, '...the internal consistency or contradictions in the [narrator's] statements about recurring themes and the way these themes relate to each other'. The significance of this inconsistency within Elias' narratives regarding whether cleanliness is a 'Lebanese' cultural trait is made clearer by exploring the reflections of the Dunedin interviewees.

Facoory (1989) for example, said 'all the Lebanese are clean' and emphasised the point several times during her interviews while La Hood (1989) reflected, 'Our people are dirt chasers - they are too clean. They clean a thing that's already clean'. Describing aspects her childhood in Dunedin, Milne (1989) recalled, 'Some of the Irish girls weren't so well looked after or as clean as the Lebanese children'. 
On several occasions throughout her interviews, Facoory (1989) referred to visits made to her Dunedin home, by a doctor of Scottish origins. She said:

'Doctor Gordon McDonald said 'Lebanese are good people. They're clean and they don't go next door to borrow sheets or anything...their homes are just like anybody else's'.

An outsider's perspective is relevant here; Carroll (1988) for example, recalled how Lebanese migrants '[had] a job to settle and make their money. I know some who are now well-to-do...[but] their grandfathers hardly had a bob or two to rub together'. When seen in the context of narratives such as the above, reflections about the 'cleanliness' of the Lebanese may be linked to their social and economic circumstances in Dunedin at that time. In the previous section on work in this chapter Dale (1989) recalled that Lebanese workers had to compete with other migrants for jobs on the 'wharf'.

It therefore begins to emerge that the reputation for cleanliness which was reflected in the narratives of the Dunedin Lebanese may have served to differentiate them from workers of other ethnic origins who were also competing for limited job opportunities. In this way, the reputation of the Lebanese for being 'clean' could be considered an adaptation in New Zealand which may have functioned in the same way as their reputation for being 'good workers'. This was also raised in the previous section by Farr (1988) whose narratives imply that Dunedin Lebanese were accepted by other New Zealanders once they had proved themselves at work. These attributes had the potential to add value to the image of Lebanese among members of the wider New Zealand community.

The divergence between Elias' views about the cultural significance of cleanliness and the views of Dunedin interviewees is also significant. Referring to his leaving employment with the Pipe and Brick Factory and taking up another position with General Motors the next day, Elias explained 'there was a lot of work in those days [during the 1950s]'. This comment implies that he did not experience the same competition for jobs as the Dunedin Lebanese whose narratives reflect their experiences in a less favourable economic context. By outwardly rejecting the idea that cleanliness is a Lebanese attribute, it could be argued that Elias' view reflects a 
more positive experience of work in New Zealand's changing social and economic circumstances.

\title{
'Something...about Lebanon...is different from other places'
}

\begin{abstract}
When we went [back] I nearly cried...Beirut was burnt...[during the civil] war. [It was] bloody terrible...I couldn't believe it!...Beirut [used to be]...the most beautiful city in the Mediterranean....St George's Hotel [was also] burnt...[it used to be ] the best hotel in the world...[the one] that gave Beirut its name.

When I was much ...younger I [would] drive....[past the landmarks in Lebanon] so many time[s]...I didn't...notice [how extraordinary they were.]....But when my family...came with me... [I felt] excitement....Something [about Lebanon] is different from other places....
\end{abstract}

These narratives convey Elias' shock at seeing first-hand the post-war destruction which had altered the Beirut of his memories. Elias' distress echoes the culture shock which emerges in his descriptions of his early experiences as a migrant in Wellington. In contrast, his third narrative also indicates the elation he experienced on the same holiday, when guiding his 'New Zealand' family around Lebanon for the first time. These reflections highlight what Kvale (1996:189) refers to as the second step of analysis in a qualitative interview, that is, when a participant discovers new meaning and connections from their experience for themselves 'on the basis of their spontaneous descriptions, free of interpretation by the interviewer'.

\section{Concluding reflections}

Aside from the many practical challenges Elias faced as a new migrant, one of the most fundamental was the sudden change in his social status. Born into the most powerful of the religious communities residing in mid twentieth century Lebanon, when he disembarked in Wellington in 1953, Elias found himself a member of a very small ethnic minority.

Elias' sense of frustration and powerlessness emerges many times throughout the narratives, which also convey his experience of isolation and culture shock. As Freeman (cited in Riessman, 2011:315) suggested; 'narratives do things, they are motivated and purposeful, if not always consciously'. While exploring Elias' narratives I also considered the way, as Riessman (2011:314) suggests, the narrator 
'position[s] audience, characters' and himself. This approach helped me to uncover deeper layers of meaning.

Reflecting on Elias' love of cowboy and western films, it is possible to identify some of the conventions of the genre in the structure and characterisation of some of his narratives. For example, by adopting the role of protagonist, or lead character, Elias often 'positions' himself as a stranger in deserted street. He encounters law-men who challenge his right to be there. Indeed as we have seen, the action of many of these narratives consists of Elias actively responding to such challenges. From his standpoint he has successfully defended himself in terms of his own cultural identity and right to be in Wellington. This action has effectively shaped the course of his life in New Zealand.

Riessman suggested (2011:318) that a narrator makes an 'identity claim':

His experience becomes the centre of attention; the story functions, as personal stories often do, to make an explanatory argument and presentation of 'self'... He can construct a positive identity in the face of what may have been [a stigmatizing illness episode]...

It is also significant that at the time of interviewing Elias had recently recovered from an illness for which he was hospitalised. Moreover his chronic health condition means that he can no longer write.

Consequently the research process, or more specifically the narrative interview method, provided Elias with the opportunity and means to voice his experiences of immigration, and of being Lebanese in New Zealand.

\section{Chapter conclusion}

Aiming for insight into the life of a Lebanese migrant in Wellington in the midtwentieth century, this chapter has explored aspects of the reflections of Elias Arraj. Focusing on those aspects of cultural inheritance which were important to Elias, this discussion has highlighted some of the obstacles he faced in Wellington, and his response to these challenges.

In order to provide context, aspects of Elias' reflections were considered alongside the archived oral histories of members of the Dunedin Lebanese community and 
sections of the relevant literature. This technique allowed further insights to emerge from the discussion.

In exploring his cultural background and motivation to leave Lebanon, Elias has demonstrated that he was not a faceless link in a migration 'chain' but rather, an individual who interpreted life events and responded to them; someone who acted according to his beliefs and values, and made his own decisions. In order to fulfil his family obligations Elias left Lebanon to visit family in New Zealand. His experience of culture shock in Wellington was profound while the restrictions on aspects of daily life seemed incomprehensible.

Elias' perceptions of a bland, unappealing Wellington social life were in marked contrast to his recollections of the cosmopolitan Beirut, and his search for variety resulted in his friendships with members of the Greek migrant community. Traditional parameters which defined communities in Lebanon, however, were still observed in Wellington, with migrant groups remaining distinct according to their religious affiliations.

With the help of his own extended family members living in Wellington and the support and encouragement he received from other members of the Lebanese community, Elias met the challenge of early set-backs. Traditions which included enjoying very close links with family who tended to live near to one another, in addition to socialising, regular visiting and offering hospitality to family members were maintained in Wellington as they had been in Lebanon.

A club formed by Lebanese migrants allowed members of the community opportunities to socialise together, but its activities were monitored by police and it was eventually closed.

Due to his Maronite Catholic faith, Elias was accepted as a Roman Catholic in Wellington, and encouraged by the priests to socialise with members of other Catholic migrant groups. St Joseph's Church in Mount Victoria was a focal point and meeting place for members of the Lebanese Maronite community in Wellington, and once he had learned sufficient English, Elias was able to form new friendships with migrants from other places of origin. 
Elias was valued for his very strong work ethic and productivity, and this helped him to gain acceptance and make friends with his employers and colleagues, as well as achieving his goal of home ownership and providing for his family.

The concept of a Lebanese 'work ethic' along with a reputation for 'cleanliness' may have helped migrants gain employment and acceptance in New Zealand. Although attitudes on what constituted a Lebanese 'cultural trait' differed, a strong sense of a shared cultural identity emerged between Elias and the Dunedin 'Turnbull' interviewees in the findings. Considering their different life experiences, these shared aspects of a Lebanese heritage are striking.

The most important support Elias received came from the friendship and encouragement of his future wife Pauline. A New Zealand-born Lebanese, Pauline helped Elias to learn English. Ultimately it was the success of this essential relationship which lead to his decision to stay in New Zealand.

Finally, the Cedar of Lebanon continues to be a most significant 'living' symbol for Elias, as it represents, for Elias, the very strong links between his Lebanese Maronite heritage, his New Zealand-born family, and their homeland. 


\section{Thesis Conclusion}

\section{Reflections on the research design and methodology}

Aiming to cast insight on the experience of the Lebanese in Wellington in the midtwentieth century, this research has explored the reflections of Lebanese migrant Elias Arraj who arrived in Wellington in 1953. In light of Elias' understanding of his cultural inheritance this inquiry focused on aspects of his experience of immigration and re-settlement: the difficulties Elias faced as a new migrant, the way he interpreted and responded to these challenges and the avenues of support which were available to him.

Recognising that research into human experience is a complex undertaking; a constructionist framework allowed the interpretation of data within its social context. The critical orientation of the research design made it possible for me to consider the relationship between power and culture through investigating 'given' values and assumptions embedded in recorded narratives. Primary and secondary data collection methods allowed me to work inductively through employing a methodology of narrative inquiry which provided access to layers of meaning. Narrative interviews were undertaken with the prime informant, Elias Arraj and a thematic analysis of oral histories contributed by members of the Dunedin Lebanese community provided a rich secondary source on the cultural context and background for the primary narratives.

Acknowledging the constructionist, critical character of the design, a careful process of interpretation, and detailed thematic analysis of the data was undertaken. The research process was designed to be transparent and reflexive at each stage allowing me to gain insight on my own role as a researcher. The application of a constructionist critical research design has drawn attention to aspects of the migrant experience of an individual such as Elias' that often remains invisible and in so doing has brought the Wellington Lebanese community into focus. 


\section{Reflections on the research findings and process}

With little knowledge of the English language, Elias drew on his strong sense of cultural heritage together with the support that was offered by other members of the Lebanese community and overcame the significant challenges he faced as a new migrant in Wellington. Elias' experience of culture shock resulted from the marked contrast between the vibrancy of Beirut and the reality of a much smaller Wellington which has been described as homogenous and assimilationist. His affiliation with the Roman Catholic Church in New Zealand provided another source of friendship and encouragement as did his work relationships with colleagues and employers.

Outside these avenues, as a new migrant, Elias had very little contact with the wider New Zealand community. In this light it is not surprising, that much of the literature describes the Lebanese as 'quiet' or 'easily assimilated'. As most New Zealanders had no knowledge of Lebanese migrants nor of the challenges they may have faced, the Lebanese community may indeed have seemed 'invisible'.

Unlike members of Lebanese entrepreneurial families whose experiences feature in much of the available literature, Elias was not sponsored to come and work in a family venture, nor did he establish his own business. Working for employers outside the Lebanese community, he was able to retain the freedom to change jobs for his own reasons, ultimately rejecting the option of an arranged marriage to marry for love and decide to stay in New Zealand.

Gaining insight into Elias' obligation to visit family together with the sense of adventure that motivated him to leave Lebanon, shows that when it comes to employing theories to explain the decisions of individuals nothing should be considered a certainty. Reflecting on what I have learned from the interpreting aspects of Elias' narratives, I now consider that I have gained insight into aspects of his experience which may have been shared by other members of the Lebanese community. A sense of the interconnections of very close family relationships, together with the importance of a shared understanding of religious history and the symbolic links with geographical features of Lebanon including the Cedars and the land itself, all emerge from the findings. 
The research has provided me with access to a sociable, welcoming Lebanese community in Wellington whose members opened their doors to a disoriented new arrival when the city itself appeared 'closed' to him. I also gained a sense of the way that inevitable disagreements had the potential to divide a community whose support was a lifeline for migrants.

Many insights were gained from the application of the narrative method, and some of them present opportunities for future research. These include the use of qualitative methods which involve an exploration of the different forms of narratives employed by participants in compromised circumstances. Acknowledging the limits of the research also raises opportunities for further study. Although the narratives of a few women were analysed during the secondary data collection method, further primary interview research with Lebanese migrant women is needed. It would be valuable to explore the experiences of migrants from Lebanon who have arrived in New Zealand recently, including those who identify with other religious communities.

Including a secondary research method - an analysis of the Dunedin Turnbull archived histories - provided an historical context which added great resonance to the findings. The points where Elias' reflections about Lebanese cultural traits diverged from those of the Dunedin interviewees, proved to be an opportunity to glimpse the subtle changes which are expressed by narrators with regards to the collective cultural identity of migrant communities. Such variations have the potential to signal historic political and social processes, which influence the experience of migrants in a place of settlement.

With regards to the question of cultural assimilation, Elias' strong sense of his Maronite Lebanese identity and heritage was expressed clearly throughout the narrative interviews. Indeed, the findings highlight that a migrant's sense of cultural inheritance cannot adequately be considered within a specific timeframe. In other words, I could not explore what was culturally important to Elias in 1953, independently from what was important to him in 2009. As the research progressed, rather than interpreting cultural identity in terms of a linear process of change, I began to conceptualise cultural 'layers' of experience which a person constructs over time. 
Elias received many offers of hospitality from other members of the Lebanese community in Wellington - so many that he could not visit all those who opened their homes to him. I was delighted to discover during one of the interviews that my own grandfather had extended one of these invitations, and was able to appreciate symmetry in the way Elias has in turn offered hospitality to me. Throughout the interviews I was constantly surprised by the strength of perceived cultural links, despite how tenuous the link may have seemed to me. Indeed, it was the participant's perception of this linked heritage, through my grandfather, which allowed the interviews to take place.

Reflecting on my own motivation for the research together with what I have learned has been most rewarding. One of the most enlightening aspects of the findings in this sense was the importance of a grandparent's relationship with his or her grandchildren. What emerged was a sense of the way this fundamental bond links individuals with their Lebanese Maronite community and heritage. In this way, I gained insight into my own sense of wanting to find out more about the grandfather I never met. When my grandfather died as the result of an accident, I lost my 'visible' link or, as O'Shea Miles (2004:81) referred to a migrant grandparent, my 'primary cultural reference' to the Lebanese community. During the process of constructing this critically applied research however, I have come to acknowledge the effect of my Lebanese heritage, and indirectly, the influence of my grandfather on my own life. 


\section{Victoria University Ethics Approval}

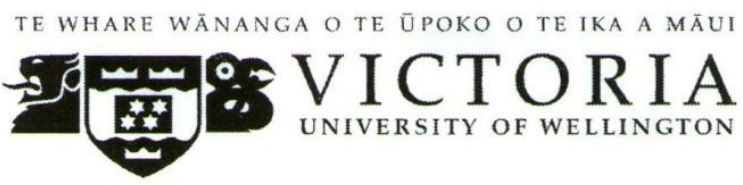

MEMORANDUM
Phone $\quad 04-4636134$

Fax $\quad 04-4635064$

Email_Rhonda.Shaw@vuw.ac.nz

\begin{tabular}{l|l}
\hline TO & Marina Fontein \\
\hline COPY TO & \\
\hline FROM & Dr Rhonda Shaw, Convener, Human Ethics Committee \\
\hline DATE & 22 April 2009 \\
\hline PAGES & 1 \\
\hline SUBJECT & $\begin{array}{l}\text { Ethics Approval: No 16481 } \\
\text { Title: The Lebanese Community in Wellington in the mid } \\
\text { Twentieth Century }\end{array}$ \\
\hline
\end{tabular}

Thank you for your application for ethical approval, which has now been considered by the Social and Cultural Studies Human Ethics Sub-Committee.

Your application has been approved and this approval continues until the end of February 2010. If your data collection is not completed by this date you should apply to the Human Ethics Committee for an extension to this approval.

Best wishes with the research.

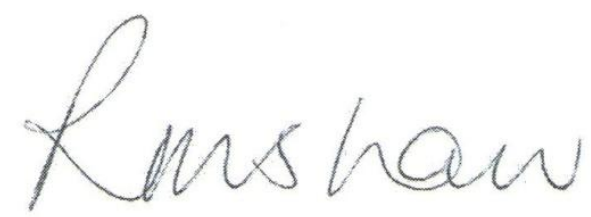

Dr Rhonda Shaw

Convener 


\title{
Participant Information Sheet
}

\author{
VICTORIA UNIVERSITY OF WELLINGTON \\ Te Whare Wānanga o te Ûpoko o te Ika a Māui
}

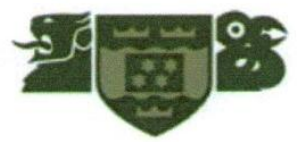

Participant Information Sheet for a Study of the Lebanese Community in Wellington in the mid Twentieth Century

Researcher: Marina Joseph Fontein: School of Social and Cultural Studies, Victoria University of Wellington

I am a Masters student in Social Science Research at Victoria University of Wellington. As part of this degree I am undertaking a research project leading to a thesis. The project I am undertaking aims to understand the experience of the Lebanese ethnic community in Wellington in the mid Twentieth Century. The University requires that ethics approval be obtained for research involving human participants.

I am inviting both men and women who emigrated from Lebanon to New Zealand in the mid Twentieth Century, and New Zealand born members of the Lebanese community to participate in this study. Participants will be asked to take part in one or two oral history interviews with myself on a range of topics which will be supplied prior to the interviews. I would like to record the interviews on audio tape.

The recorded oral history interviews will form the basis of my research project and will be transcribed, edited and analysed by myself.

It is envisaged that each interview will take approximately two hours. I anticipate the venue for these interviews will be the participant's own place of residence. Should participants wish to be interviewed elsewhere, I am happy to make alternative arrangements and reimburse the participants travel costs if required.

Participants will be given an edited summary of their interview, and have the opportunity to provide feedback before the results are analysed. My contact details are included at the conclusion of this form. I will make contact with you when they are available.

Participants will also be given a summary of the results of this research when it is completed. 


\section{APPENDIX B}

page 2

Should any participants feel the need to withdraw from the project, they may do so up to a month after the data has been collected.

The thesis will be submitted for marking to the School of Social and Cultural Studies and deposited in the University Library. Some part of the research project may eventually be included in a non-fiction publication.

Interview notes will be destroyed two years after the end of the project.

One of the benefits of this research project concerns its potential contribution to an archive of material about the Lebanese Community in Wellington. Participants will have the choice as to whether they wish their tape-recorded interviews to be made available to the Alexander Turnbull Library as a lasting resource. In this case, the data will not be kept confidential.

If you have any questions or would like to receive further information about the project, please contact me at 8 Ellwood Place, Churton Park, Wellington, phone 04 4774725 or my supervisor, Dr Annette Beasley, at the School of Social and Cultural Studies, Victoria University of Wellington, P.O. Box 600, Wellington.

Thank you for your consideration.

Marina Joseph Fontein 


\title{
Consent To Participate In Research
}

APPENDIX C

\author{
VICTORIA UNIVERSITY OF WELLINGTON \\ Te Whare Wānanga o te Ūpoko o te Ika a Mãui

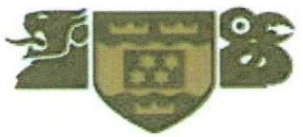

Consent to Participation in Research

The Lebanese Community in Wellington in the Mid Twentieth Century

I have been given and have understood an explanation of this research project. I have had an opportunity to ask questions, and have them answered to my satisfaction. I understand that I may withdraw myself or any information I have provided from this project up to one month after it has been collected.

VI agree that my interview will be audio-taped by the researcher.

$\checkmark \mathrm{I}$ consent to my name being used and information or opinions which I have given being attributed to me in any reports on this research.

$\square$ I would like the tape recordings of my interviews to be lodged with the Alexander Turnbull Library of New Zealand under my name.

would like to receive an edited summary of the interview transcript when it is completed.

VI would like to receive a summary of the results of this research when it is completed.

I agree to take part in this research Name of participant: Elias Arraj Date: 13.08 .09
(please print clearly)

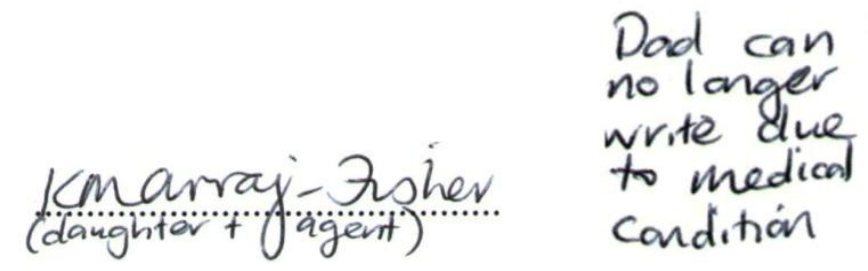




\section{Interview Questions}

\section{$1^{\text {st }}$ July 2009}

\section{Interview questions to prompt narrator...}

Can you please tell me your full name?

How do you spell your name?

What was the year and place of your birth?

Do you know why you were called....?

What do you know about your family name?

What was your mother's name?

What was your father's name?

How many brothers and sisters do you have?

When did you / your family choose to come to New Zealand?

Why did you / your family choose to come to New Zealand?

Do you know which ship you or your family came over on?

Do you know which port the ship left from / when they left?

Did you stop at another port / country before you came to New Zealand?

Were there other family members / friends already settled here?

Did other family members / friends arrive after you?

Were you helped or supported by other family members or friends who had already settled here?

Do you speak / understand Arabic?

What language did you speak at home?

Did you or your parents speak English when you first came to New Zealand?

Did you or your parents go back to visit Lebanon? 
Can you describe your earliest memory?

What can you remember about your grandparents / aunts / uncles?

Do you know any family stories about the war / the great depression?

Where did you attend school?

Were there other Lebanese children there? Did you play together?

What games did you play?

Have you heard of the Arabic word shirakee?

Can you remember social occasions shared with other Lebanese families? Activities / picnics?

Can you tell me about Lebanese weddings / christenings / First Communions / funeral?

Where did you live in Wellington when you were growing up / raising your own family?

Did other Lebanese families live there?

Do you remember anything about the Lebanese Club in Wellington?

Were you a member?

Do you remember any activities: games etc, functions that happened there?

\section{Community / ethnic relations}

What about other communities - do you remember other ethnic groups - i.e. Irish / Italian / European / Chinese / Other? Do you remember any 'trouble' between groups?

Did you ever experience any prejudice at school / outside of school?

\section{Marriage / Children}

If you are married can you tell me if you married a Lebanese person?

Do your children / grandchildren know any Arabic words?

\section{Cultural traditions / symbols}

Do your family have any special keepsakes from Lebanon? Souvenirs? Photos?

Do you have any memories of the nuns / priests / other? Did they have any special contact with Lebanese families? 


\section{Lebanese identity}

What did growing up Lebanese in new Zealand mean to you?

How would you describe your nationality / ethnicity? New Zealander / Lebanese, Mt Lebanon?

Have you any memories of your village?

If you have never been to Lebanon, what did you learn about it from your parents?

How would you describe values / ethics held by the Lebanese? Do you think these are different from members of other communities?

Do you or your family still maintain any links with people in Lebanon?

\section{Work and employment / business}

What do you remember about work? Your parents work / grandparents work?

Do you remember any property owned by members of the Lebanese community in Wellington? i.e. Boarding houses etc

Do you know of any businesses owned by Lebanese people in the mid twentieth century ? Did you own a business? Did members of the Lebanese community patronise your business?

What can you tell me about sponsorship / apprenticeship / patronage within the community?

\section{Stories}

Do you remember any stories / family stories about Lebanese personalities or events in Wellington?

I would love to hear them.

Did you ever hear of my grandfather Joe Maroon Joseph, his father Maroon Habib Joseph, or his mother Nujedi Maree? (or grandmother Sadie Maree.) 


\section{References:}

Akoorie, M.E.M. (2007), 'Lebanese entrepreneurs in New Zealand', in Lèo-Paul Dana (ed.), Handbook of Research on Ethnic Minority Entrepeneurship: a Coevolutionary View on Resource Management, Cheltenham: Edward Elgar, pp.754-779.

Alldred, P. \& Gillies, V. (2002), 'Eliciting Research Accounts: Re/Producing Modern Subjects?', in B.J. Mauthner (ed.), Ethics in Qualitative Research, London: Sage, pp 146-165.

Ali, S. \& Kelly, M. (2010), 'Ethics and social research', in C.Seale (ed.), Researching Society and Culture $2^{\text {nd }}$ Edition, 2010: Sage, pp 115-128.

Anderson, K. \&. Jack, D. (1998), 'Learning to listen; interview techniques and analyses', in R. Perks \&. A. Thomson (eds), The Oral History Reader, London: Routledge, pp.157-162.

Anonymous, (1992), Evening Post Collection, Wellington, PA Coll-7327.

Arraj-Fisher, Karen (2009), Interviews, July-August.

Ayres, L. (2008), Narrative Interview', the Sage Encyclopedia of Qualitative Research Methods, accessed January 18, 2010, from: <http://www.sageereference.com/research/Article_n277.html>

Bailey, C. (2007), A Guide to Qualitative Field Research, Thousand Oaks: Pine Forge Press.

Beaglehole, A. (1988), A Small Price to Pay: Refugees from Hitler in New Zealand 1936-46. Wellington: Allen \& Unwin.

Beaglehole, A. (1990), 'Facing The Past', PHD Thesis, Victoria University of Wellington.

Beaglehole, A. (1990), Facing the Past: Looking Back at Refugee Childhood in New Zealand 1940s - 1960s. Wellington: Allen \& Unwin.

Beasley, A. (2006). 'Kuru truths: obtaining Fore narratives', Fieldmethods, vol.18, no.1., pp21-42.

Beasley, A. (2010), 'Supporting the investigation of kuru in New Guinea in the 1960s: the narratives of four wives', In Press.

Berger, P. L. (1963), Invitation to Sociology. A Humanistic Perspective. New York: Anchor Books. 
Bouzaid, G. (1992), Diary of George Bouzaid, Wellington: Bouzaid Family Reunion Committee.

Bouzaid T., 'The Bouzaid Family: A history of the pioneers and their descendants from Lebanon', the Bouzaid Family, website, http://bouzaidfamily.org/index.html>

Božić-Vrbančić, S. (2008), Tarara: Croats and Maori in New Zealand: Memory, Belonging, Identity, Dunedin: Otago University Press.

Briton, E. (1988), Interview, Presbyterian Support Otago Community History Programme: Walker Street oral history project, (OHA-6409), Alexander Turnbull Library.

Carroll, R. (1988), Interview, Presbyterian Support Otago Community History Programme: Walker Street oral history project, (OHA-6407), Alexander Turnbull Library.

Carspecken, P. F. (2008), 'Critical Research', the Sage Encyclopedia of Qualitative Research Methods, accessed Jan 18, 2010, from: <http://www.sageereference.com/research/Article_n88.html>

Cedars of Lebanon Club, Cedars of Lebanon Club Dunedin New Zealand, website from http://www.cedarsoflebanon.org.nz

Cheek, J. (2008). 'Research Design', the Sage Encyclopedia of Qualitative Research Methods, accessed August 18, 2011, from: <http://www.sageereference.com/view/research/n384.xml>

Cobban, H. (1985), The Making of Modern Lebanon, London: Hutchinson.

Crotty, M. (1998), The Foundations of Social Research, Crows Nest: Allen \& Unwin.

Dale, N. (1989), Interview, Presbyterian Support Otago Community History Programme: Walker Street oral history project, (OHA-6403), (OHInt-0951-04), Alexander Turnbull Library.

De Bres, J. (1997), 'The Boat People', The de Bres Family New Zealand, website, accessed http://www.debres.co.nz/boatpeople.html>

Doornbos, J. (2006), Swapping Country and Culture in the 1950s: Dutch Born Women of the 1950's Look Back, Mana: Inlet View Press.

Duggan, J. (2007), Saint Joseph's Parish Te Aro and Mount Victoria, Wellington: St Joseph's Mt Victoria Parish.

Eddé, Anne-Marie, (2000), 'Lebanon - Matāwila, de facto, Lebanon in History', accessed November 18, 2009, from 
http://www.jrank.org/history/1853/Lebanon.html">Lebanon- Matāwila, de facto, Lebanon in History $</ a>$

Facoory, S. (1989), Interview, Presbyterian Support Otago Community History Programme: Walker Street oral history project, (OHA-6401), (OHInt-0951-02), Alexander Turnbull Library.

Farr, A. (1988), Interview, Presbyterian Support Otago Community History Programme: Walker Street oral history project, (OHA-6406), (OHInt-0951-07), Alexander Turnbull Library.

Farry, M. (2000), 'An Inquiry into the Cultural Identity of Second and Third Generation "Lebanese New Zealanders", unpublished PhD thesis, The University of Otago.

Friedman, J. (2003), 'Assimilation', the Sage Encyclopedia of Community, accessed September 3, 2008, from: http://www.sageereference.com/community/Article_n28.html>

Frisch, M. (1990), A Shared Authority, New York: State University of New York Press.

Garlough, C. L. (2003), 'Immigrant Communities', The Sage Encyclopedia of Community, accessed September 2, 2008, from: http://www.sageereference.com/community/Article_n240.html>

Gilmour, D. (1983), Lebanon The Fractured Country, Oxford: Martin Robertson \& Company.

Given, I. (1988), Interview, Presbyterian Support Otago Community History Programme: Walker Street oral history project, (OHA-6408), Alexander Turnbull Library.

Glesne, C. (2006), Becoming Qualitative Researchers, Boston: Pearson.

Grbich, C. (2004), New Approaches in Social Research, London: Sage.

Green, A. (2004), 'Oral history and history', in Remembering, Writing Oral History, (eds) A. Green \& M. Hutching, Auckland University Press: Auckland, pp 1-8.

Guest,G., Bunce, A., and Johnson, L. (2006), 'How Many Interviews Are Enough? An experiment with Data Saturation and Variability', Sage Journals Online: Fieldmethods, vol.18, no.1, 59-82, from: http://fmx.sagepub.com/content/18/1/59.

Hareven, T. (1996), 'The Search for Generational Memory', in D. Dunaway \& W. Baum (eds), Oral History: An Interdisciplinary Anthology 2nd edition, Walnut Creek: Altamira Press, pp. 241-256. 
Hitti, P. (1957), Lebanon in History, London: MacMillan.

Hutching, M. (1999), Long Journey for Sevenpence: Assisted Immigration to New Zealand from the United Kingdom 1947-75, Wellington: Victoria University Press.

Jack, D. (1998), 'Interview Analyses: Listening For Meaning', in R. Perks \&. A. Thomson (eds), The Oral History Reader, London: Routledge, pp. 164-171.

Kasanji, L. (1982), 'The Gujaratis in Wellington: the study of an ethnic group', unpublished M.A. thesis, Victoria University of Wellington.

Kayal, P. (1973), 'Religion and Assimilation: Catholic "Syrians" in America', International Migration Review, vol.7, no.1, 409-425.

Kelly, M. (2010), 'Research design and proposals' in C. Seale (ed.), Researching Society and Culture $2^{\text {nd }}$ Edition, (pp. 130-142). London: Sage.

Kvale, S. (1996), Interviews: An Introduction to Qualitative Interviewing. California: Sage.

LaHood, S. (1989), Interview, Presbyterian Support Otago Community History Programme: Walker Street oral history project, (OHA-6400), (OHInt-0951-01), Alexander Turnbull Library.

Leckie, G. (2008), 'Researcher Roles', the Sage Encyclopedia of Qualitative Research Methods, accessed 18 January, 2010, from: <http://www.sagereference.com/research/Article_n389.html>

Manying Ip (1996), Dragons on the Long White Cloud, Birkenhead: Tandem.

Masgoret, A. \& Ward, C. (2008), 'Attitudes toward immigrants, immigration, and multiculturalism in New Zealand: a social psychological approach', International Migration Review, accessed 16 July, 2010, from:

$<$ http://www3.interscience.wiley.com.helicon.vuw.ac.nz/cgibin/fulltext/119400393/ma...>

Mauthner, M., (2002), in Ethics in Qualitative Research, (eds) Mauthner, M., Birch, M., Jessop, J., \& Miller, T. London: Sage.

McCullough, G. (2004), 'Life and times: diaries, letters and autobiographies', in G. McCulloch (ed.), Documentary Research: In Education, History and the Social Sciences, London: Routledge:Social Research and Educational Studies Series, pp. 101-127.

McDonald, A. (2004), Lebanon's children: a pictorial history of the Otago/Southland Lebanese Community, Dunedin: Cedars of Lebanon Club.

McGill, D. (1982), The Other New Zealanders, Wellington: Mallinson Rendel. 
Miller, T. \& Bell, L. (2002), 'Consenting to what? Issues of access, gate-keeping and informed consent', in M. Mauthner, M. Birch, J. Jesspo, \& T. Miller (eds), Ethics in Qualitative Research London: Sage. pp. 53-70.

Milne, J. (1989), Interview, Presbyterian Support Otago Community History Programme: Walker Street oral history project, (OHA-6404), (OHInt-0951-05), Alexander Turnbull Library.

Mirepoix, C. (1969), Lebanon in Pictures, New York: Sterling Publishing.

Mishler, E. (1999), Storylines: Craftartists' Narratives of Identity, Cambridge, MA: Harvard University Press.

Moodabe, M., 'Moodabe, Michael Joseph - Biography', Dictionary of New Zealand Biography, Te Ara - the Encyclopedia of New Zealand, updated 1-Sep-10; from: http://www.TeAra.govt.nz/en/biographies/4m59/

Moodabe, M. (2000), Peanuts and Pictures: the Life and Times of M.J. Moodabe, Auckland: The Moodabe Family.

O'Brien, M. (1993), 'Social Research and Sociology', in N. Gilbert (ed.), Researching Social Life, London: Sage. pp. 1-17.

Ongley, P. \& Pearson, D. (1995), 'Post-1945 international migration: New Zealand, Australia, and Canada compared', International Migration Review, vol.29, no.3.

O'Shea-Miles, C. (2004), 'The Women of Irishtown', in A. Green \& M. Hutching (eds) Remembering, Writing Oral History, Auckland: Auckland University Press, pp. 77-89.

Page, D. \& Farry, J. (1990), The hawkers: a family story, Dunedin: Shinbone Alley.

Page, D., 'Coory, Shirefie - Biography', Dictionary of New Zealand Biography. Te Ara - the Encyclopedia of New Zealand, updated 1-Sep-10; from: http://www.TeAra.govt.nz/en/biographies/2c31/1/

Patton, M. (2002), Qualitative Research and Evaluation Methods 3rd Edition, Thousand Oaks: Sage.

Phillips, J. (2006), 'History of immigration', in J. Phillips (ed.) Settler and Migrant Peoples of New Zealand: Te Ara - the Encyclopedia of New Zealand, Albany: David Bateman, pp.20-42.

Presbyterian Support Otago Community History Programme: Walker Street oral history project, (1988-89), in Alexander Turnbull Library, (OH Coll-0951).

Raleigh Yow, V. (2005) 'Varieties of Oral History Projects: Community Studies' in V. Raleigh Yow (ed.) Recording Oral History Toronto: Altamira Press, pp. 188210. 
Richards, L. \&. Morse, J. (eds) (2007), User's Guide to Qualitative Methods.

Thousand Oaks: Sage.

Riessman, C.K. (1993), Narrative Analysis, Newbury Park, CA: Sage.

Riessman, C.K. (2003), 'Narrative interviewing', in the Encyclopedia of Social

Science Research Methods, accessed January 11, 2010, from: www.sageereference.com/socialscience/Article_n612.html>

Riessman, C. K. (2011), 'What's different about narrative inquiry? Cases, categories and contexts', in D. Silverman (ed.), Qualitative Research 3rd Edition, London: Sage, pp. 310-330.

Sanders, M.C. (1980), 'The Lebanese Community in Dunedin', unpublished B.A. Honours Thesis, University of Otago.

Scott, D. (2002), A Stake in the Country: Assid Abraham Corban and his Family, 1892-2002. Auckland: Reed Books.

Scuro, J. (2004) 'Exploring personal history: a case study of an Italian immigrant woman', The Oral History Review, vol. 31, p. 43.

Stechman, Lucia Arraj (2009), Interviews, July-August.

Taher, M. (1970), 'The Asians', in K. Thomson \& A. Trlin (eds), Immigrants in New Zealand, Palmerston North: Massey University, pp. 38-64.

Thornton, C.B. (1968), 'The Lebanese, Chinese and Dutch communities in Dunedin City', unpublished MA thesis, The University of Otago.

Trlin, A. (1979), Now Respected, Once Despised, Palmerston North: Dunmore Press.

Veitch, J. \& Tinawi, D.(2006) 'Middle Eastern Peoples', in J. Phillips (ed.) Settler and Migrant Peoples of New Zealand: Te Ara - the Encyclopedia of New Zealand, Albany: David Bateman, pp. 208-211.

Veitch, J. \& Tinawi, D. (2009) 'Middle Eastern peoples - assimilation and recent arrivals', accessed November 5 2009, in Te Ara - the Encyclopedia of New Zealand: from http://www.TeAra.govt.nz/en/middle-eastern-peoples/2

Wenger, G. C. (2002), 'Interviewing older people' in J. Gubrium \& J. Holstein (eds), Handbook of Interview Research, Thousand Oaks: Sage, pp. 259-279.

Zamir, M. (1985), The Formation of Modern Lebanon, London: Croom Helm.

Ziadeh, N. (1957), Syria and Lebanon, London: Ernest Benn. 